6 4 6

\title{
TORC2 dependent phosphorylation modulates calcium regulation of fission yeast myosin.
}

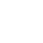

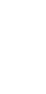

Karen Baker ${ }^{1}$, Irene A. Gyamfi ${ }^{1}$, Gregory I. Mashanov², Justin E. Molloy², Michael A. Geeves ${ }^{1}$ and Daniel P. Mulvihill ${ }^{1,3}$

${ }^{1}$ School of Biosciences, University of Kent, Canterbury, Kent, CT2 7NJ, UK. 2

2 The Francis Crick Institute, 1 Midland Road, London NW1 1AT, UK

${ }^{3}$ Author for correspondence e-mail: d.p.mulvihill@kent.ac.uk Tel: $+44(0) 1227827239$

Key words: pombe, endocytosis, calmodulin, Tor kinase.

Running Title: Phosphorylation \& calcium co-dependent myosin regulation 


\section{Abstract}

31 All cells have the ability to respond to changes in their environment. Signalling

32 networks modulate cytoskeleton and membrane organisation to impact cell

33 cycle progression, polarised cell growth and multicellular development

34 according to the environmental setting. Using diverse in vitro, in vivo and single

35 molecule techniques we have explored the role of myosin-1 signalling in

36 regulating endocytosis during both mitotic and meiotic cell cycles. We have

37 established that a conserved serine within the neck region of the sole fission

38 yeast myosin-1 is phosphorylated in a TORC2 dependent manner to modulate

39 myosin function. Myo1 neck phosphorylation brings about a change in the

40 conformation of the neck region and modifies its interaction with calmodulins,

41 Myo1 dynamics at endocytic foci, and promotes calcium dependent switching

42 between different calmodulin light chains. These data provide insight into a 43 novel mechanism by which myosin neck phosphorylation modulates acto-

44 myosin dynamics to control polarised cell growth in response to mitotic and 45 meiotic cell-cycle progression and the cellular environment. 


\section{Introduction}

The actin cytoskeleton underpins cellular organisation by maintaining cell shape and through the transmission of mechanical signals between the cell periphery and nucleus, to influence protein expression, organisation and cellular architecture in response to needs of the cell. Myosins, actin-associated motor-proteins, work in collaboration to facilitate global cytoskeletal organisation and a plethora of transport processes including cell migration, intracellular transport, tension sensing and cell division (O'Connell et al, 2007). While there are many classes of myosin, each contains an actin binding ATPase motor domain, which exerts force against actin, a lever arm or neck region that contains light chain binding $I Q$ motifs, and a tail region which specifies cargo binding and other molecular interactions.

Although different classes of myosin perform very different cellular functions they all operate by the same basic mechanism, whereby the motor domain undergoes cyclical interactions with actin coupled to the breakdown of ATP. Each molecule of ATP that is converted to ADP and inorganic phosphate can generate movement along actin of between $5-25 \mathrm{~nm}$ and force of up to $5 \mathrm{pN}$. Regulation of acto-myosin motility is multi-faceted (Heissler \& Sellers, 2016a), combining regulatory pathways operating via the actin track (historically called thin-filament regulation), or myosin-linked regulation (historically called thick filament regulation) which is often mediated via phosphorylation of the heavy chain or light chain(s) or by calcium-regulation of light chain binding (Heissler \& Sellers, 2016b). It has been shown that phosphorylation at the conserved "TEDS" motif within the myosin motor domain of class 1 myosin affects actomyosin interaction (Bement \& Mooseker, 1995); phosphorylation within the tail region of class 5 myosin controls cargo binding (Rogers et al, 1999), whereas phosphorylation of class 2 myosin light chains and/or heavy chain can change the folded state of the heavy chain, affecting both actin interaction and ability to form filaments (Redowicz, 2001; Kendrick-Jones et al, 1987; Pasapera et al, 2015). So, phosphoregulation of myosin can occur in the head, neck and tail regions and also the light chains and its effects are manifold and vary across myosin classes and between paralogues within the same class. Its effect on 
motile function is still not fully understood for many myosins, especially within yeast (East \& Mulvihill, 2011).

The fission yeast, Schizosaccharomyces pombe, genome encodes for 5 myosin heavy chains from classes 1, 2, and 5 (Win et al, 2002), representing the basic subset of these actin-associated motor proteins found in eukaryotic cells. The single class 1 myosin, Myo1, is a $135 \mathrm{kDa}$ protein, with motor domain, neck region (with two canonical IQ motifs) and a $49 \mathrm{kDa}$ tail region containing a, so-called, tail-homology-2 domain, PH domain, SH3 domain and a carboxylterminal acidic region that associates with and activates the Arp2/3 complex to nucleate actin polymerisation (Lee et al, 2000). The myosin motor has a conserved TEDS site, phosphorylated by a Ste20 protein kinase, to modulate the protein's ability to associate with actin (Attanapola et al, 2009). Myo1 associates with membranes, primarily at sites of cell growth, where it is required for endocytosis, actin organisation and spore formation (Sirotkin et al, 2005; Lee et al, 2000; Itadani et al, 2007).

Calmodulin or calmodulin-like light chains associate with the IQ motifs within the myosin neck, providing a mechanism to regulate the length and stiffness of the lever arm (Trybus et al, 2007) and behaviour of the motor domain (Adamek et al, 2008). Calmodulins are ubiquitous calcium binding proteins that associate with and regulate the cellular function of diverse proteins. Calcium associates with up to four EF hand motifs within the calmodulin molecule to bring about a change in its conformation to modulate its affinity for IQ motifs within binding partner proteins (Crivici \& Ikura, 1995). S. pombe encodes for two calmodulin like proteins, Cam1 and Cam2 (Takeda \& Yamamoto, 1987; Itadani et al, 2007). Cam1 is a typical calmodulin that associates with IQ domain containing proteins in a calcium dependent manner, to affect functions as diverse as endocytosis, spore formation, cell division or maintaining spindle pole body integrity (Takeda \& Yamamoto, 1987; Moser et al, 1995; 1997; Itadani et al, 2010). Unlike Cam1, Cam2 is not essential and is predicted to be insensitive to calcium, however like Cam1 it has been reported to regulate Myo1 (Sammons et al, 2011; Itadani et al, 2007). While cells lacking Cam2 show defects in spore formation they have no significant growth-associated phenotypes during the vegetative growth cycle. 
112 TOR (Target of Rapamycin) signaling plays a key role in modulating cell growth

113 in response to changes in cell cycle status and environmental conditions

114 (Laplante \& Sabatini, 2012). The mTOR kinase forms two distinct protein

115 complexes TOR complex 1 (TORC1) and TORC2, each defined by unique

116 components that are highly conserved across species. While both TORC1 and

117 TORC2 have been implicated in the control of cell migration and F-actin

118 organisation (Liu \& Parent, 2011), TORC2 plays a key role in regulating the

119 actin cytoskeleton in yeasts, Dictyostelium discoideum and mammalian cells

120 (Jacinto et al, 2004; Baker et al, 2016; Lee et al, 2005). While the basic principle

121 of control of each regulatory signal (e.g. phosphorylation and calcium signalling)

122 are understood, the interplay between parallel modes of regulation is relatively

123 unknown. S. pombe, contains both TORC1 and TORC2 complexes (Petersen,

124 2009).

125 In the current study, we have used molecular cell biological, biochemical and

126 single molecule techniques to help identify and characterise a novel TORC2

127 phosphorylation-dependent system for regulating calcium-dependent switching

128 of different calmodulin light chain(s) binding to the neck region of Myo1. We

129 have established the contribution that each calmodulin plays in regulating this

130 conserved motor protein and how they affect the conformation of the myosin

131 lever arm. We propose a concerted mechanism of regulation by both calcium

132 and phosphorylation that controls motility and function of Myo1 in response to

133 signals controlling cell cycle progression. 


\section{Results}

135 Fission yeast myosin-1 is phosphorylated within the IQ neck domain.

136 Analysis of extracts from exponentially growing fission yeast cells indicates its 137 sole class I myosin, Myo1, is subject to multiple phosphorylation events (Figure 138 1A). Phosphoproteomics studies (Carpy et al, 2014; Wilson-Grady et al, 2008)

139 revealed a conserved phosphoserine residue located within the IQ motif 140 containing neck region of class I \& V myosins (Figure 1B). The location of this 141 AGC family kinase consensus phosphoserine site (Pearce et al, 2010) has the 142 potential to impact myosin activity and function by affecting conformation of the 143 lever arm as well as light chain binding. A phosphospecific antibody was raised 144 to confirm phosphorylation of the Myo1 serine 742 (Myo1 ${ }^{\mathrm{S742}}$ ), and established 145 that it is phosphorylated in a TORC2 signalling and growth media dependent 146 manner (Figure 1C-E). Consistent with the TORC2 dependent pathway 147 modulating cell growth in response to media quality (Petersen \& Nurse, 2007), 148 replacing the serine with a non-phosphorylatable alanine residue within 149 myo1.S742A cells resulted in an inability to inhibit growth when cultured in 150 media containing minimal nitrogen (Figure 1F).

\section{Phosphorylation modulates Myo1 lever arm length.}

153 As serine 742 lies within the IQ motif containing neck region of myosin-1, we 154 explored whether Myo1 ${ }^{5742}$ phosphorylation affects calmodulin binding and 155 conformation of the neck region. Isoforms of the $\mathrm{Ca}^{2+}$ sensitive fission yeast 156 calmodulin (Cam1 and Cam1.T6C) were isolated in their native amino157 terminally (Nt) acetylated forms using bacteria co-expressing the fission yeast 158 NatA amino- $\alpha$-acetyl-transferase complex (Eastwood et al, 2017). A FRET 159 based fusion was generated with CyPet donor and YPet acceptor fluorophores 160 (Nguyen \& Daugherty, 2005) juxtaposed around the Cam1 protein to monitor $161 \mathrm{Ca}^{2+}$ dependent changes in Cam1 conformation (Figure 2A). This FRET-Cam1 162 fusion (Figure 2B), and Nt-acetylated IAANS labelled Cam1.T6C (Figure 2C) 163 established $\mathrm{Ca}^{2+}$ binding brings about a change in the Cam1 conformation. 164 Calculated pCa values for the Cam1-FRET (Figure 2B pCa 50 : 6.12), reflect 165 global change in Cam1 conformation, while the IAANS dependent pCa (Figure 
$1662 \mathrm{C} \mathrm{pCa} 50$ : 6.54) reflects $\mathrm{Ca}^{2+}$ dependent changes in the local environment at

167 the amino lobe of Cam1. Quin-2, fluorescence of which increases upon $\mathrm{Ca}^{2+}$

168 binding (Tsien, 1980), was used to establish $\mathrm{Ca}^{2+}$ ions release from Cam1 with

1693 distinct rate constants $\left(137,12.9\right.$ and $\left.2.0 \mathrm{~s}^{-1}\right)$ (Figure 2D).

170 To characterise Cam1 binding to the IQ neck region of the fission yeast myosin-

171 1, recombinant FRET constructs were produced in which CyPet and YPet were

172 separated by individual or both Myo1 IQ motifs (Myo1 ${ }^{\mathrm{IQ}}{ }_{-}$-FRET, Myo1 ${ }^{\mathrm{IQ}}$-FRET,

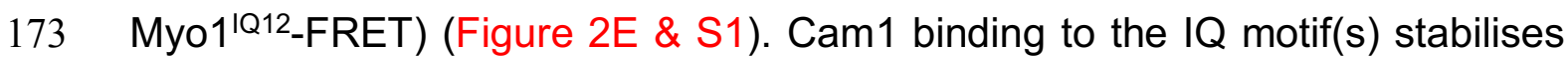

174 the a-helix and results in a calcium regulated drop in FRET signal (Figure 2E-

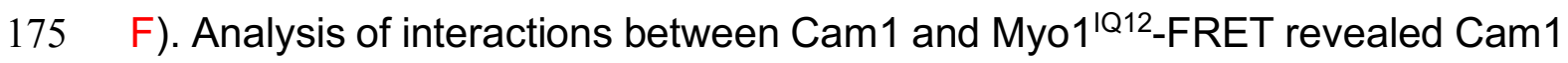

176 molecules associated with the combined Myo1 $1^{1 \mathrm{Q} 12}$ motifs with 2 distinct phases,

177 each contributing $50 \%$ of the overall change in signal (Figure 2G). The first

178 Cam1-Myo1 $1^{\mathrm{IQ} 12}$ binding event corresponds to an affinity of less than $0.1 \mu \mathrm{M}$

179 (binding was too tight to calculate affinity with higher precision), while the

180 second event correlates with an approximately 10-fold weaker binding affinity

$181(0.68 \mu \mathrm{M})$. This association was seen to be sensitive to calcium ( $\mathrm{pCa}$ of 5.87 )

182 (Figure 2I), illustrating Cam1 only associates with Myo1 in low cellular $\mathrm{Ca}^{2+}$

183 concentrations. Interestingly while Cam1 was seen to bind tightly to Myo1 ${ }^{\mathrm{IQ} 1}$

184 alone $\left(\mathrm{K}_{d}<0.1 \mu \mathrm{M}\right)$, no detectable association was observed for the equivalent 185 single Myo1 ${ }^{\mathrm{IQ} 2}$ motif (Figure 2J). Together these data are consistent with a

186 sequential cooperative binding mechanism by which the stable residency of

187 Cam1 in the first IQ position is required before calmodulin can bind to Myo $1^{\mathrm{IQ} 2}$.

188 Replacing serine 742 within the IQ neck region with a phosphomimetic 189 aspartate residue had no significant impact upon the affinity, calcium sensitivity 190 or cooperative nature of the interaction between Myo1 and Cam1 (Figure 2G).

191 However, the phosphomimetic replacement resulted in a change in maximum

192 FRET signal upon Cam1 binding ( $F_{\max } 46.05$ vs 31.64) (Figure 2G \& H) 193 indicating Myo1 ${ }^{5742}$ phosphorylation changes the conformation of the lever arm 194 upon Cam1 binding, rather than modulating the affinity for Cam1.

196 Phosphorylation regulates Myo1 dynamics and endocytosis.

197 To explore in vivo Myo1 and calmodulin dynamics we generated prototroph S. 
pombe strains in which endogenous myo1, cam1, or cam2 genes were fused to cDNA encoding for monomeric fluorescent proteins (Figure 3A). Using highspeed $(20 \mathrm{~Hz})$ single molecule TIRF analysis we explored how Myo1 ${ }^{\mathrm{S742}}$ phosphorylation impacts Myo1 and Cam1 dynamics and function within the cell. Myo1 and Cam1 associated with the cell membrane in two distinct ways: we observed rapid transient associations of single molecules at the cell membrane, characterised by low-intensity single stepwise changes in intensity as well longer endocytic events which were much brighter and had a very different time-course. Single molecules of Myo1 and Cam1 bound transiently at the cell membrane and moved with low mobility $\left(0.03 \mu \mathrm{m}^{2} \mathrm{~s}^{-1}\right), \sim 10$-times slower than diffusion of integral membrane proteins (Mashanov et al, 2010). The individual, diffraction-limited fluorescent spots appeared and disappeared in a stepwise fashion (i.e. within a single video frame). Event durations were exponentially distributed with mean lifetime of $2.2 \mathrm{~s}^{-1}(\mathrm{n}=152)$ (Movie 1). In contrast, during endocytic events, the fluorescence signal increased gradually, rising to a peak amplitude consistent with $\sim 45$ molecules of mNeongreen.Myo1 (rate $\sim 13$ molecules. $\mathrm{s}^{-1}$ ), which dwelled for $\sim 6 \mathrm{~s}$, before falling to baseline (rate $\sim 14$ molecules. $\mathrm{S}^{-1}$ ) (Figure 3B, Movie 2). The estimated number of Myo1 molecules is lower than reported in an earlier study (Sirotkin et al, 2010) perhaps due to differences in imaging techniques, as TIRF imaging illuminates the specimen to a depth of $\sim 100 \mathrm{~nm}$ whereas confocal imaging would extend to $>400 \mathrm{~nm}$ ). The duration ( $T_{\text {dur }}$ ) of endocytic events (measured as described in the Methods) was $13.84 \mathrm{~s}+/-0.39$ (mean +/- SEM, n=50) (Figure 3C) and while there was significant variation in the maximum mNeongreen.Myo1 intensity (2373 +/155), there was no correlation between maximum intensity and event duration (Figure 3D). Fluorescence intensity dynamics of Cam1.GFP during endocytic events were similar to mNeongreen.Myo1, but $T_{\text {dur }}$ was significantly shorter $(P$ $<0.0001), 10.99 \mathrm{~s}+/-0.21(\mathrm{n}=52)$ while the peak intensity was roughly double that measured for mNeongreen.Myo1 and equivalent to 90 GFP molecules (Figure 3E) consistent with Cam1 occupying both IQ sites within the Myo1 neck region. The briefer event duration observed for Cam1 might be explained by Cam1 dissociating from Myo1 before Myo1 leaves the endocytic patch. This idea was confirmed using two-colour imaging of mNeongreen.myo1 cam1.mCherry cells which showed Myo1 and Cam1 arrived simultaneously at 
232 the endocytic patch, but Cam1.mCherry disassociated $\sim 3 \mathrm{~s}$ before

233 mNeongreen.Myo1 (Figure 3F, S2).

234 Analysis of Myo1 and Cam1 dynamics in myo1.S742A cells during endocytosis 235 revealed Myo1 ${ }^{\text {S742A }}$ had average assembly/disassembly rates and plateau 236 intensity identical to wild type Myo1, but $\mathrm{T}_{\text {dur }}$ was $1.5 \mathrm{sec}$ shorter (12.3s +/- 0.31 $237 \mathrm{n}=67$ ) (Figure 3G \& S2). Consistent with the in vitro data, the myo1.S742A 238 mutation did not impact on the ability of Cam1 molecules associating at both IQ 239 motifs, as average assembly/disassembly rates, and plateau intensity for Cam1 240 were the same in both wild type and myo1.S742A cells. However, we found 241 that Myo1 ${ }^{\text {S742A }}$ and Cam1 proteins disassociated simultaneously and somewhat 242 earlier during the endocytic event in this strain.

243 These TIRF imaging data were consistent with widefield 3D-timelapse imaging 244 that showed lifetimes of Myo1 and Cam1 foci were shorter in myo1.S742A cells 245 when compared to $m y 01^{+}$(Figure $\left.3 \mathrm{H}\right)$. In contrast, while the myo1.S742A allele 246 did not affect accumulation of Cam2 or LifeACT to sites of endocytosis (Figure $2473 \mathrm{I}$ ), the rate of endocytosis differs between old end and new ends of myo1248 S742A cells compared to wild type (Figure 4A). Therefore, while Myo1 ${ }^{\mathrm{S742}}$ 249 phosphorylation does not impact assembly of Myo1-Cam1 endocytic foci, it 250 regulates myosin activity to change the function of the ensemble of endocytic 251 proteins during bipolar growth.

253 Myo1 $\mathbf{S 7 4 2}$ is phosphorylated in a cell cycle dependent manner to 254 regulate polarised cell growth.

255 Upon cell division fission yeast cells grow exclusively from the old cell end that 256 existed in the parental cell. At a point during interphase (called New End Take 257 Off -NETO) there is a transition to a bipolar growth (Mitchison \& Nurse, 1985). 258 This cell cycle switch in growth pattern correlates precisely with a parallel 259 redistribution of endocytic actin patches (Marks \& Hyams, 1985). As the 260 myo1.S742A allele only affected actin dynamics at the old cell end during 261 bipolar growth we examined whether this post-translational modification was 262 subject to cell cycle dependent variance. Analysis of extracts from cell division 263 cycle mutants arrested in G1 (cdc10.v50 cells) or late G2 (cdc25.22 cells) 
264 revealed Myo1 ${ }^{\text {S742 }}$ is phosphorylated in a cell cycle dependent manner (Figure

265 4B). This was confirmed by monitoring Myo1 ${ }^{\text {S742 }}$ phosphorylation in cells 266 synchronised with respect to cell cycle progression (Figure S3). These data 267 established that Myo $1^{\$ 742}$ phosphorylation peaks in early interphase (G1 cells), 268 prior to the transition to a bipolar growth pattern, and steadily decreases until 269 becoming undetectable towards the end of G2. Analysis of growth kinetics 270 revealed myo1.S742A cells grow slower than wild type (Figure 4C), and have 271 a longer average length (myo1 ${ }^{+}: 9.77 \pm 1.77 \mu \mathrm{m}$; myo1.S742A: $13.2 \pm 2.47 \mu \mathrm{m}$. 272 t-test $>99 \%$ significance $\mathrm{n}>500$ ). In addition, a significant proportion of 273 myo1.S742A cells demonstrate polarity defects, with $24.7 \%$ of cells having a 274 bent morphology (i.e. growth deviates by $>5^{\circ}$ from longitudinal axis), compared 275 to $1 \%$ seen in wild type (Figure 4D-E). Consistent with these observations, 276 myo1.S742 mutants exhibit defects in the transition from monopolar to polar 277 growth. Cell wall staining revealed a significantly higher proportion of 278 myo1.S742A cells exhibit monopolar growth compared to equivalent wild type, 279 indicating disruption in the switch from monopolar to bipolar growth (Figure 4E). 280 This was confirmed by tracking the cellular distribution of the actin patch 281 marker, Sla2/End4, following cell division. Sla2 failed to redistribute to the newly 282 divided end of myo1.S742A cells during interphase (Figure 4F). Together these 283 data show that cell cycle variation in Myo1 ${ }^{\mathrm{S742}}$ phosphorylation modulates the 284 myosin lever arm to regulate endocytosis and polarised growth.

\section{Cam2 associates with internalised endosomes and not Myo1 during} vegetative growth.

288 Myo1 has been reported to associate with a second calmodulin like protein, 289 Cam2, via its second IQ motif (Sammons et al, 2011). However, our data 290 indicate Cam1 occupies both Myo1 IQ motifs during endocytosis. Widefield 291 microscopy revealed Myo1 and Cam1 dynamics (Figure 5A) at endocytic foci 292 differ significantly from Cam2 which is recruited to sites of endocytosis later 293 than Myo1 and Cam1, but prior to budding off, where, like CAPZA Acp1, Sla2 and 294 actin, it remains associated with laterally oscillating internalised endosomes 295 (Figure 5B-C). Similarly, simultaneous imaging of Cam1 and Cam2 in 296 cam1.mCherry cam2.gfp cells revealed each protein localises to many foci 
297 lacking the other calmodulin, indicating differences in the timing of endocytic 298 recruitment (Figure 5D). While Cam1 recruitment to endocytic foci is abolished 299 in the absence of Myo1 (Figure 5E), the intensity, volume and number of Cam2 300 foci increases in the absence of Myo1 (Figure 5F Table 1). However, 301 internalisation and lateral "oscillating" dynamics of Cam2, and actin were 302 dependent on Myo1 (Figure 5F \& G). Therefore, while Cam1 and Cam2 both 303 localise to sites of endocytosis, they appear to do so at different times, and each 304 have differing Myo1 dependencies.

305 TIRF analysis revealed on average a total of $\sim 30$ Cam2 molecules recruit to 306 each endocytic foci, and the kinetics of its recruitment to foci differ significantly 307 to that observed for both Myo1 and Cam1. Cam2 often had a linear binding 308 relationship (Figure 6A), which contrasts to the sigmoidal profiles observed for 309 Myo1 and Cam1 (Figure 3C \& E). TIRFM confirmed Cam2 remained associated 310 with endocytic vesicles after they were internalised and their connection with 311 the cell membrane was broken (Movie 3). Background corrected intensity 312 traces of Cam2 dynamics at the membrane patch before, during, and after the 313 end of endocytosis showed the signal rapidly dropped to baseline $(<1 \mathrm{~s})$ (Figure 314 6A), with the Cam2 labelled vesicles remaining visible close to the membrane 315 at the limit of the evanescent field. A large number of these mobile internalised 316 Cam2 labelled vesicles were seen moving within the cytoplasm with relatively 317 low cytosolic background signal (Movie 3), indicating much Cam2 associates 318 with endocytic vesicles and remains bound to mature endosomes. During the 319 latter stages of endocytosis, Cam2 was internalised on the endosome while 320 Myo1 remained at the plasma membrane during endosome abscission (Sirotkin 321 et al, 2010; Berro \& Pollard, 2014; Picco et al, 2015). Timing of the Myo1 and 322 Cam2 fluorescence signals did not correlate; Cam2 was associated with the 323 endocytic vesicle moving away from the cell surface during endocytosis and 324 remaining associated with the early endosome at the time of scission. Whereas, 325 Myo1 and Cam1 remained immobile and stayed close to the cell surface 326 (plasma membrane) throughout the endocytic cycle.

327 To correlate Myo1-Cam1 association at sites of endocytosis with scission of the 328 endosome into the cytoplasm, we followed Cam1 and Cam2 dynamics 329 simultaneously in cam1.mCherry cam2.gfp cells (Movie 4). An average curve 
generated from profiles of $>30$ complete individual endocytic events (Figure 6B)

331 shows Cam2 moves away from the cell surface shortly after Cam1 leaves but 332 before Myo1, with the time of abscission ( $T_{\text {scis }}$ ) occurring on average $13.4 \mathrm{sec}$ 333 after the event starts ( $\left.\mathrm{T}_{\text {start }}\right)$. Therefore endosome scission takes place during 334 the Myo1 disassembly phase, and around the time Cam1 dissociates from 335 Myo1.

336 Intriguingly, while the overall distribution of Myo1 and Cam1 appeared 337 unaffected in cam $2 \Delta$ cells, the number, volume and intensity of foci were 338 significantly reduced (Figure 6C-D Table 1). TIRF-based analysis of the spatial 339 distribution of Myo1 and Cam1 at endocytic foci revealed that Cam1 organised 340 into more dispersed foci in the absence of Cam2 (Figure 6E-F), indicating Cam2 341 plays a role in organising the Myo1-Cam1 complex at the plasma membrane.

343 Serine $\mathbf{7 4 2}$ phosphorylation increases the affinity of a single Cam2 for 344 Myo1.

345 In vitro analysis revealed two Cam2 molecules can associate with the 346 unphosphorylated Myo1 $1^{\mathrm{IQ12}}$ region (Figure 6G) with 2 distinct phases. In 347 contrast to Cam1 binding, $70 \%$ of the signal change is associated with an 348 affinity of $1.10 \mu \mathrm{M}$. The smaller tighter signal change is not accurately 349 measurable, but the combined change in signal is consistent with 2 binding 350 events. As predicted from sequence analysis, Cam2 was not seen to associate 351 with calcium (Figure 2D), and its conformation and interactions with Myo1 were 352 insensitive to the divalent cation (Figure 6H). Like Cam1, Cam2 had a higher 353 affinity for the first IQ motif $(0.4 \mu \mathrm{M})$ than both IQ12 together, and did not bind 354 to IQ2 alone (Figure 2J). Cam1 calcium binding, as measured by IAANS 355 labelling or change in Quin-2 fluorescence were unaffected by Cam2, while gel 356 filtration and fluorescence binding assays provided no evidence of a direct 357 physical interaction between the two proteins (Figure S4). Interestingly a 358 difference was observed in fluorescence amplitudes between Cam1 and Cam2 359 binding to the IQ12 motif, may indicate an impact upon lever arm length, (Figure $3606 \mathrm{H}$ ), potentially providing a mechanism to directly control Myo1 motor activity. 361 Myo1 ${ }^{\mathrm{S742}}$ phosphorylation had no measurable impact upon the dynamics and 
distribution of Cam2 within fission yeast cells undergoing normal vegetative growth (Figure 7A Table 1). In contrast, in vitro analysis revealed Cam2 was only able to occupy one of the two IQ motifs in the Myo1 ${ }^{\text {S742D-IQ12 }}$ protein, be that with an increased affinity to the unphosphorylated protein $(0.25 \mu \mathrm{M})$ (Figure $6 \mathrm{G})$, indicating Cam2 impacts Myo1 function outside of the vegetative life cycle.

\section{Cam1 and Cam2 associate with Myo1 during meiosis.}

Calcium levels within log phase yeast cells are relatively low (100-200 nM) (Ma et al, 2011; Miseta et al, 1999), and provides favourable conditions for Cam1 to associate with Myo1 ( $\mathrm{pCa}$ - 5.87). Analysis of cell fluorescence indicated the relative abundance of Myo1 : Cam1 : Cam2 within the $S$. pombe cell to be 0.2 : 1.45 : 1 (Table 1), which is similar to the ratios defined by quantitative proteomic analysis of $0.45: 1.56: 1$ (Marguerat et al, 2012). Similarly, image analysis of Cam1-GFP fluorescence revealed $1.7 \%$ of Cam1 to be associated with discrete foci within cells (Table 1), 40\% of which is dependent upon Myo1, with the majority associating with the SPB (Figure 5D). This indicates $\sim 0.68 \%$ of cellular Cam1 associates with Myo1 at dynamic endocytic foci. These relative protein levels, binding affinities and low $\mathrm{Ca}^{2+}$ concentrations favour Cam1 binding to Myo1, over Cam2 at both IQ sites (Figure 7B), consistent with in vivo observations.

While $\mathrm{Ca}^{2+}$ levels are low during vegetative growth, sporadic prolonged calcium bursts occur upon pheromone release during mating (Carbó et al, 2016; lida et al, 1990), and levels elevate significantly ( 10 fold) during the subsequent meiosis and sporulation (Suizu et al, 1995). Cam1 would be less likely to bind to Myo1 in these conditions ( $\mathrm{pCa} 5.87$ ). Myo1 ${ }^{\mathrm{S} 742}$ is phosphorylated from $\mathrm{G} 1$, through cell fusion, persisting until completion of spore formation (Figure 7C). In addition Cam2 abundance increases significantly in relation to Cam1 during G1 upon mating and entry into meiosis (Mata \& Bähler, 2006; Mata et al, 2002). These provide conditions that would favour Myo1-Cam2 interactions over Cam1 (Figure 7B), which is consistent with both Myo1 and Cam2 playing important role at the leading edge of forespore membrane formation during meiosis (Toya et al, 2001; Itadani et al, 2007). Consistent with this prediction, 
394 Myo1, Cam1, Cam2 foci lifetime and dynamics differ significantly to those 395 observed in vegetative cells $(P<0.0001)$, lasting significantly longer $(>1 \mathrm{~min})$ in 396 meiotic and sporulating cells (Figure 7D \& E). In contrast to vegetative cells, 397 during meiosis and subsequent spore formation, like Myo1 and Cam1, Cam2 398 and actin foci were less dynamic, lacking any oscillation and remain in a fixed 399 position with significantly longer lifetime than within actively growing cells 400 (Figure 7D, Movie 5-8).

401 Finally, we used the myo1.S742A allele to explore the impact of Myo1 ${ }^{\text {S742 }}$ 402 phosphorylation on Myo1, Cam1 and Cam2 dynamics and function during 403 meiosis. In contrast to wild type, the lifetime of Cam1 foci were significantly 404 shorter in myo1.S742A cells, and did not correlate with Myo1 and Cam2 405 dynamics, both of which differed significantly from myo $1^{+}$cells (Figure 7F). The 406 majority of Cam2 foci remained present in the cell for greater than 2 mins in 407 meiotic cells lacking Myo1 ${ }^{\text {S742 }}$ phosphorylation, which also differed significantly 408 from Myo1 ${ }^{\text {S742A }}$ dynamics, indicating normal Cam1 and Cam2 interactions with 409 Myo1 were abolished. Consistent with myo1.S742A cells grown to stationary 410 phase in minimal media (Figure 1F), heterothallic $\left(h^{90}\right) \mathrm{G} 1$ arrested nitrogen 411 starved myo1.S742A cells failed to inhibit polar growth (Figure 7G), mating cells 412 accumulated with abnormal shmoo tips, and meiosis often resulted in cells with 413 too few unequally sized spores (Figure $7 \mathrm{G}$ arrowheads). This spore defect 414 phenotype is similar to that observed in cam2 $\Delta$ cells (Itadani et al, 2007), which 415 is consistent with a model whereby increase in cellular $\mathrm{Ca}^{2+}$ and Myo1 ${ }^{\mathrm{S} 742}$ 416 phosphorylation are both key for Cam2 association with and regulation of Myo1.

417 These data support a model by which changes in calcium levels and TORC2 418 dependent phosphorylation status provide a simple two stage mechanism for 419 modulating motor activity by modifying lever arm length as well as switching 420 calmodulin light chain preference to regulate myosin function in response to 421 changing needs of the cell (Figure 7B). 
422

423

424

425

427

428

429

430

431

432

433

434

435

437

438

439

440

441

442

443

444

\section{Discussion}

Myosins are subject to diverse systems of regulation, which include composition of the actin track, cargo and light chain interactions, as well as phosphorylation. Here we describe a newly discovered mechanism by which phosphorylation of the myosin heavy chain (Figure 1) regulates light chain specificity, lever arm conformation and flexibility, to modulate and control cellular function. During the vegetative life cycle, within basal levels of cellular calcium, the fission yeast myosin-1 preferentially associates with two molecules of the calcium regulated calmodulin light chain Cam1 (Figures 2 \& 3). During early stages of the cell cycle TORC2 dependent phosphorylation of the Myo1 neck region, to which the light chain(s) bind, changes the length of the Cam1 associated lever arm to moderate its activity to regulate the rate of endocytosis (Figure 4).

During the sexual cycle, Myo1 $1^{S 742}$ remains phosphorylated (Figure 7). This combined with the increase in cytosolic $\mathrm{Ca}^{2+}$ levels leads to a switch in light chain preference to a single molecule of the calcium insensitive calmodulin like, Cam2. The single Cam2 molecule is likely to bind IQ1 of S742 phosphorylated Myo1, as comparison with the structure of the $I Q$ region of Myosin-1 and calmodulin (Lu et al, 2014), phosphorylation of S742 is likely to impact calmodulin interactions at the $1^{\text {st }} I Q$ position. Furthermore, our data reveals that Cam2 is unable to associate with IQ2 alone, as it is necessary for one calmodulin to occupy IQ1 in order for a second to bind to IQ2. This switch in light chain occupancy may provide a mechanism to change the stiffness of the Myo1 neck region (i.e. the "lever arm") and thereby modulate the movement and force it produces during the acto-myosin ATPase cycle and/or the loadsensitivity of its actin-bound lifetime.

While Myo1 is capable of associating with phospholipid membranes via its Plekstrin Homology $(\mathrm{PH})$ domain, in vivo data suggests that this alone is not sufficient to enable a stable interaction at the plasma membrane (Figure 8A). The build-up of the early endocytic markers, such as Pan1 or Sla1, are necessary to catalyse its nucleation to early endocytic patches allowing Myo1 foci to form at the site of membrane invagination. This is consistent with our observation that once initiated, Myo1-Cam1 foci do not collapse, but go on to 
complete the endocytic event (Figure 8B) (Sun et al, 2015; Barker et al, 2007). Similarly, the size of this early marker "patch" has a direct impact upon the number of Myo1 molecules recruited to the plasma membrane, which is consistent with the role of Pan1 in enhancing the Arp2/3 actin nucleating activity of myosin-1 foci in yeast (Barker et al, 2007).

The local concentration of Myo1 at the endocytic patch appears critical, rather than the absolute number of Myo1 molecules, as the latter does not affect the duration of the Myo1 driven event. Indeed the duration of Myo1's residency at the plasma membrane is driven by Cam1 and phosphorylation regulated neck length. Interestingly neither of these factors affect the rate of Myo1 or Cam1 recruitment or disassociation from the membrane.

Therefore the size of the Pan1 patch determines the number of Myo1 molecules necessary to generate a critical local concentration of Arp2/3 nucleated actin filaments (Figure 8C) (Barker et al, 2007). At the critical concentration myosin heads are able to interact with actin filaments nucleated from either adjacent Myo1 tails or WASP activated Arp2/3 complexes, tethered to the membrane via molecules such as the Talin like Sla2 (Figure 8D) (Sirotkin et al, 2005; 2010). The Myo1 is then primed to act as a tension sensor against the actin filament, as it pushes against the membrane of the internalised endosome, which grows against the significant $0.85 \mathrm{MPa}(8.3 \mathrm{~atm})$ turgor pressure within the cell (Minc et al, 2009) (Figure 8E). While observations within budding yeast indicate motor activity from a ring of myosins at the lip of the endosome (Mund et al, 2018) is necessary for endocytic internalisation the mechanism by which the myosin interacts with actin to facilitate this is unknown (Sun et al, 2006).

The number of Myo1 molecules at the plasma membrane foci remains constant, as the membrane is internalised, until 2 seconds after Cam1 disassociates from Myo1 (Figure 8F). While the trigger for Cam1 release is unknown, the rapid ensemble nature of the event indicates it is likely to be initiated by a rapid localised spike in calcium. This could perhaps be driven by a critical level of membrane deformation coupled to calcium influx - similar to processes proposed for mechano-transduction and the role of mammalian myosin-1 within the stereocilia of the inner ear (Adamek et al, 2008; Batters et al, 2004). Alternatively, mechanical forces acting on Myo1 may drive Cam1 dissociation. 
Genetics studies from budding yeast indicate that calmodulin mutants, unable to bind $\mathrm{Ca}^{2+}$, release normally from myosin-1 (Geiser et al, 1991). Research using mammalian brush border myosin-1, indicates that changes in lipid composition of membranes to which the motor is associated are sufficient to displace calmodulin from the IQ region (Hayden et al, 1990). In fission yeast this change in lipid could be rapidly triggered by PI4-kinase phosphorylation (Cam2 is the light chain for Pl4 kinase (Sammons et al, 2011)). This is consistent with timing of Cam2 membrane recruitment and could go some way to explain why Myo1 foci are more dispersed in absence of Cam2.

Once Cam1 detaches from the Myo1 molecule, the neck loses rigidity (Figure $8 \mathrm{~F}$ ), reducing tension between the myosin motor and actin filament, causing it to detach rapidly from F-actin (Lewis et al, 2012; Mentes et al, 2018). Given the off-rate of single Myo1 molecules from the plasma membrane is $\sim 2 \mathrm{sec}^{-1}$ (Figure 3B), lack of association with actin would mean that Myo1 would leave the endocytic patch a second or so after losing its Cam1 light chain. Together these events account for the 2 sec delay between disappearance of Cam 1 and Myo1 from the membrane. The same drop in tension at the plasma membrane could provide the signal for scission of the endosome (Palmer et al, 2015).

The conformation and rigidity of the Myo1 lever arm would therefore play a key role in modulating the tension sensing properties of the motor domain. This is consistent with our data, where wild type phosphorylatable Myo1 resides at the membrane $\sim 1.8 \mathrm{sec}$ longer than unphosphorylated Myo1 ${ }^{\text {S742A }}$ (Figure S2). Phosphorylation-dependent changes in the conformation of the myosin neck provide a simple mechanism to modulate the rate of endocytosis according to the size and needs of the cell. Similarly, in the presence of $\mathrm{Ca}^{2+}$ and Myo1 ${ }^{\mathrm{S742}}$ phosphorylation, a single Cam2 resides at IQ1 motif of the neck (Figure 7B), again modulating neck conformation adjacent the motor domain as well as allowing flexibility within the carboxyl half of the neck region. This would provide a relatively tension insensitive motor, that stalls against the actin polymer, and would therefore persist significantly longer at the endocytic foci, as observed here (Figure 7E). These changes in lever arm properties change the overall rate of endocytosis, as observed in differences for actin labelled endosomes to internalise (Figure 4A). 
521 Thus phosphorylation-dependent changes in the calcium regulated

522 conformation and rigidity of the myosin lever arm could provide a universal

523 mechanism for regulating the diverse cytoplasmic activities and functions of

524 myosin motors within all cells. 


\section{Materials and Methods}

Yeast cell culture: Cell culture and maintenance were carried out according to (Moreno et al, 1991) using Edinburgh minimal medium with Glutamic acid nitrogen source (EMMG) unless specified otherwise. Cells were cultured at 25 ${ }^{\circ} \mathrm{C}$ unless stated otherwise and cells were maintained as early to mid-log phase cultures for 48 hours before being used for analyses. Genetic crosses were undertaken on MSA plates (Egel et al, 1994). All strains used in this study were prototroph and listed in Supplementary Table 1.

Molecular Biology: cam1 ${ }^{+}$(SPAC3A12.14), cam1.T6C and cam2 ${ }^{+}$ (SPAC29A4.05) genes were amplified as Nde1 - BamH1 fragments from genomic S. pombe DNA using 0226/o227 and o393/o394 primers and cloned into pGEM-T-Easy (Promega, Madison, WI, USA). After sequencing the subsequent genes were cloned into pJC20 (Clos et al., 1990) to generate bacterial calmodulin expression constructs. DNA encoding for the FRET optimized fluorophores CyPet and YPet (Nguyen and Daugherty, 2005) were each amplified using primers 0405 / 0406 and 0403 / o404 respectively. 0406 also incorporated DNA at the 3' end of the CyPet ORF encoding for the first IQ motif of the Myo1 neck region, while 0404 included DNA encoding a Gly3His6 tag at the 3' of the YPet ORF. The two DNA fragments were cloned into pGEMT-Easy in a three-way ligation reaction to generate pGEM-CyPet-Myo1IQ1YPet. The CyPet-Myo1 ${ }^{1 \mathrm{Q} 1}-$ YPet DNA was subsequently sequencing and cloned as a Nde1 - BamH1 fragment into pJC20 (Clos \& Brandau, 1994) to generate pJC20CyPet-Myo1 ${ }^{\text {IQ1 }}$-YPet. Complementary oligonucleotides 0425 \& 0426 were annealed together and ligated into BgllI - Xho1 cut pJC20CyPet-Myo1 ${ }^{\text {IQ1 }}$ YPet to generate pJC20CyPet-Myo1 ${ }^{1 \mathrm{Q} 12}$-YPet. Similarly, complementary oligonucleotides $0429 \& 0430$ were annealed together and subsequently ligated into Sal1-Bglll cut pJC20CyPet-Myo1 ${ }^{\text {IQ1 }}$-YPet and the subsequent Xho1 fragment was excised to generate pJC20CyPet-Myo1 ${ }^{1 \mathrm{Q} 2}$-YPet. Site directed mutagenesis was carried out using pJC20CyPet-Myo $1^{\mathrm{IQ} 12}-Y$ Pet template and 0427 \& 0428 primers to generate pJC20CyPet-Myo $1^{1 \mathrm{Q} 12}$ S742D-YPet. Complementary oligonucleotides 0449 \& 0450 were annealed together and

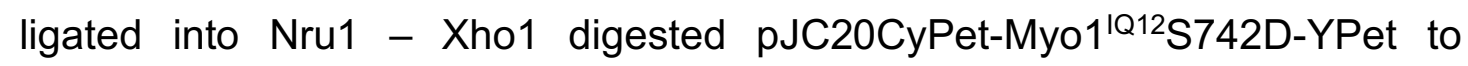
generate pJC20CyPet-Myo1 $1^{1 \mathrm{Q} 12}$ S742A-YPet. All plasmids were sequenced 
559

upon construction. Strains with fluorophore tagged alleles of cam1 ${ }^{+}$and cam2 $2^{+}$ were generated as described previously using appropriate template and primers (Bähler et al, 1998). Strains in which the myo1.S742A, myo1.S742D, mNeongreen-myo1, mNeongreen-my01.S742A, or mNeongreen-my01.S742D alleles replaced the endogenous myo $1^{+}$gene (SPBC146.13c) were generated using a marker switching method (Maclver et al, 2003). Oligonucleotides are described in Supplementary Table 2.

Protein expression \& purification: All recombinant proteins were expressed and purified from BL21 DE3 E. coli cells, except Cam1 proteins where BL21 DE3 pNatA cells (Eastwood et al, 2017) were used to allow amino-terminal acetylation (Figure S1). Calmodulin purification: Cell lysates were resuspended in Buffer A (50 mM Tris, $2 \mathrm{mM}$ EDTA, $1 \mathrm{mM}$ DTT, $0.1 \mathrm{mM} \mathrm{PMSF}, \mathrm{pH} 7.5$ ) and precleared by high speed centrifugation (48,500 RCF; $30 \mathrm{~min} ; 4^{\circ} \mathrm{C}$ ), before ammonium sulphate was added to the supernatant at $35 \%$ saturation, incubated for 30 minutes at $4{ }^{\circ} \mathrm{C}$. Precipitated proteins were removed by centrifugation $\left(48,500 \mathrm{RCF} ; 30 \mathrm{~min} ; 4{ }^{\circ} \mathrm{C}\right)$. For Cam1 purifications the precipitation cleared supernatant was added to a pre-equilibrated $10 \mathrm{ml}$ phenyl sepharose (CL-4B) column (Buffer B: $50 \mathrm{mM}$ Tris, $1 \mathrm{mM}$ DTT, $1 \mathrm{mM} \mathrm{NaN}, 5$ $\mathrm{mM} \mathrm{CaCl}_{2}, \mathrm{pH}$ 8.0), washed in 4 volumes of Buffer $\mathrm{B}$ before eluted as fractions in Buffer $\mathrm{C}$ (50 mM Tris, $1 \mathrm{mM}$ DTT, $1 \mathrm{mM} \mathrm{NaN}_{3}, 5 \mathrm{mM}$ EGTA, pH 8.0). For Cam2 purification the precipitation cleared supernatant underwent a second round of ammonium sulphate precipitation and clearing, and the subsequent supernatant subjected to isoelectric precipitation $(\mathrm{pH} \mathrm{4.3)}$ and centrifugation (48,500 RCF: 30 minutes; $4^{\circ} \mathrm{C}$ ). The resultant pellet was resuspended in Buffer $\mathrm{A}$, heated to $80{ }^{\circ} \mathrm{C}$ for 5 minutes and denatured proteins removed by centrifugation (16,000 RCF; 5 min). His-tagged proteins were purified in native conditions using prepacked, pre-equilibrated $5 \mathrm{ml} \mathrm{Ni}^{2+}$ columns.

Fast reaction kinetics: All transient kinetics were carried out using a HiTech Scientific DF-61 DX2 Stopped Flow apparatus (TgK Scientific, Bradford-uponAvon, UK) at $20^{\circ} \mathrm{C}$. All data was acquired as the average of $3-5$ consecutive shots and analysed using the KineticStudio software supplied with the equipment. Quin-2 fluorescence was excited at $333 \mathrm{~nm}$ and used a Schott GG445 cut off filter to monitor fluorescence above $445 \mathrm{~nm}$. IAANS (2-(4'- 
592 (iodoacetamido)anilino)-naphthalene-6-sulfonic acid) was excited at $335 \mathrm{~nm}$ 593 and fluorescence was monitored through a GG455 filter. For the FRET 594 measurements, CyPet was excited at $435 \mathrm{~nm}$ and YPet emission was 595 monitored through a combination of a Wrattan Gelatin No12 (Kodak) with a 596 Schott GG495 nm filter to monitor fluorescence at $525-530 \mathrm{~nm}$.

597 Fluorescence spectra: Emission spectra were obtained using a Varian Cary 598 Eclipse Fluorescence Spectrophotometer (Agilent Technologies, Santa Clara, 599 CA) using a $100 \mu \mathrm{l}$ Quartz cuvette. For FRET measurements samples were 600 excited at $435 \mathrm{~nm}$ (CyPet excitation) and emission was monitored from 450 $601600 \mathrm{~nm}$ with both slits set to $1 \mathrm{~nm}$. Affinity experiments were carried out using $6021 \mu \mathrm{M}$ IQ-FRET protein with varying concentrations of Cam1 or Cam2 in a final 603 volume of $100 \mu \mathrm{l}$ in analysis buffer of $140 \mathrm{mM} \mathrm{KCl}, 20 \mathrm{mM} \mathrm{MOPS}, \mathrm{pH} 7.0$ with 604 or without $2 \mathrm{mM} \mathrm{MgCl} 2$ and with $2 \mathrm{mM}$ of $\mathrm{EGTA}, \mathrm{CaCl}_{2}$ or $\mathrm{Ca}^{2+}-\mathrm{EGTA}$ as 605 required.

606 Live cell imaging: Live cell widefield fluorescence imaging was undertaken as 607 described previously (Baker et al, 2016). For Total Internal Reflection 608 Fluorescence Microscopy (TIRFM) S. pombe cells were immobilized on №1, $\varnothing$ $60925 \mathrm{~mm}$ lectin coated coverslips and placed into imaging chambers filled with 610 EMMG medium. A previously described custom TIRF Microscope (Mashanov 611 et al, 2003) was used to image individual cells at a rate of $20 \mathrm{fps}$ in either single 612 of dual colour mode. Lasers: $488 \mathrm{~nm} / 100 \mathrm{~mW}$ and $561 \mathrm{~nm} / 150 \mathrm{~mW}$ (Omicron, 613 Germany); emission filters 525/50 nm and 585/29 nm, dichroic mirror $552 \mathrm{~nm}$ 614 (Semrock, NY); all lenses and mirrors (Thorlabs, NJ), except two $\varnothing 3 \mathrm{~mm}$ 615 mirrors (Comar Optics, UK) which directed light in and out of the $100 \times 1.45$ NA 616 objective lens (Olympus, Japan). Sequences of images were captured using 617 one or two iXon897BV cameras (Andor Technology, UK) with custom made 618 acquisition software. 100\% laser power (488 nm) was used to image individual 619 mNeongreen-Myo1 and Cam1-GFP molecules. The laser intensity was 620 reduced to $\leq 20 \%$ during endocytosis imaging experiments to minimize 621 photobleaching. All imaging was undertaken at $23^{\circ} \mathrm{C}$.

622 Image analysis: Widefield data was analysed using Autoquant software 623 (MediaCybernetics, Rockville, MD, USA). All 3d image stacks were subjected 624 to blind $3 \mathrm{~d}$ deconvolution before analysis. Average size and number and 
cellular distribution of foci were calculated from all foci present within $\geq 30$ cells

626 for each sample examined. Timing of foci events were calculated from

627 kymographs generated in Metamorph software (Molecular Devices, Sunnyvale,

628 CA, USA). The proportion of cells displaying a bent cell phenotype was 629 determined from more than $>350$ calcofluor $\left(1 \mathrm{mg} \cdot \mathrm{ml}^{-1}\right)$ stained cells for each

630 strain. Bent cells were defined by a deviation in the direction of growth of $>5^{\circ}$

631 from the longitudinal axis. TIRF data analyses, including single molecule

632 detection and tracking, was undertaken using GMimPro software (Mashanov \&

633 Molloy, 2007). Endocytic events were identified by creating an image

634 representing the standard deviation of each pixel over the whole video

635 sequence (known as a "z-projection"). Bright spots in this image correspond to

636 regions of the yeast cell that showed large intensity fluctuations. Regions of 637 interest (ROIs) $0.5 \mu \mathrm{m}$ diameter (5x5 pixels) were created to enclose the site 638 of endocytosis and changes in the averaged ROI intensity over the entire video record were saved for future analysis. To correct for local variation in

640 background signal, the average intensity in a region $1.5 \mu \mathrm{m}$ diameter around 641 the endocytosis site (but not including the central ROI) was subtracted. Data 642 from ROls that were contaminated by other endocytosis events, occurring in 643 close proximity and close in time, were manually excluded from the analysis. It 644 was critical to identify accurately the start and end of each endocytosis event 645 so that individual traces could be averaged. To facilitate this, the rising and 646 falling phases of the intensity trace were fitted with a straight line (60 data 647 points, $3 \mathrm{sec}$ duration), see Figure $3 \mathrm{C}$ for example. The intercept of this line 648 with the baseline intensity gave the $t_{\text {start }}$ and $t_{\text {end }}$ values and event duration $649\left(T_{\text {dur }}=t_{\text {end }}-t_{\text {start }}\right)$ (see Figure $\left.6 A\right)$. Intensity traces for each given condition were 650 synchronised to the starting point ( $t_{\text {start }}$ ) and averaged (except Cam2-GFP 651 traces which were synchronised using tstart measured from simultaneously 652 acquired Cam1-mCherry signal). Similarly, traces were synchronised to their 653 end point ( $\left.t_{\text {end }}\right)$ and averaged. The mean duration of the events ( $\left.T_{\text {dur }}\right)$ for each 654 condition was then used to reconstruct the mean intensity changes with 655 calculated errors for event amplitude and timing (Table 2). Since the falling and 656 rising phases of most events fitted well to a simple linear equation, the slope of 657 the fitted lines was used to estimate the rate of accumulation and dissociation 658 of the fluorescent molecules. As Cam2-GFP remained bound to the endocytic 
659 vesicle, when vesicle scission occurred intensity fell rapidly to zero as the

660 vesicle diffused from the TIRF evanescent field; the time of scission was

661 defined as $t_{\text {scis }}$ (Figure 6C). Single particle tracking was performed using, 662 GMimPro (Mashanov \& Molloy, 2007) (ASPT module) so that the paths (or 663 trajectories) of individual Myo1 molecules bound to cell membrane could be 664 traced. Trajectories were analysed to yield mean intensities for individual 665 NeonGreen and eGFP labelled proteins, which could be used to estimate the 666 number of fluorescently-tagged molecules associated with each endocytotic 667 event. Intensity-versus-time plots were generated from averages of $>30$ foci for 668 each protein in each genetic background examined.

\section{Acknowledgements}

673 We thank Professors M. Balasubramanian, I. Hagan, P. Nurse, C. Shimoda and 674 T. Pollard for strains; and Dr Ben Goult for stimulating discussions and 675 comments on the manuscript. This work was supported by the University of 676 Kent and funding from the Biotechnology and Biological Sciences Research 677 Council (BB/J012793/1 \& BB/M015130/1), a Royal Society Industry Fellowship 678 to DPM; a CASE industrial bursary from Cairn Research Ltd to KB and by the 679 Francis Crick Institute which receives core funding from Cancer Research UK 680 (FC001119), the UK Medical Research Council (FC001119) and the Wellcome 681 Trust (FC001119) GIM and JEM. 
683

684

685

686

687

688

689

690

691

692

693

694

695

696

697

698

699

700

701

702

703

704

705

706

707

708

709

710

711

712

713

714

715

716

717

718

719

720

721

\section{References}

Adamek N, Coluccio LM \& Geeves MA (2008) Calcium sensitivity of the cross-bridge cycle of Myo1c, the adaptation motor in the inner ear. Proceedings of the National Academy of Sciences 105: 5710-5715

Attanapola SL, Alexander CJ \& Mulvihill DP (2009) Ste20-kinase-dependent TEDS-site phosphorylation modulates the dynamic localisation and endocytic function of the fission yeast class I myosin, Myo1. J. Cell. Sci. 122: 3856-3861

Baker K, Kirkham S, Hálová L, Atkin J, Franz-Wachtel M, Cobley D, Krug K, Macek B, Mulvihill DP \& Petersen J (2016) TOR complex 2 localises to the cytokinetic actomyosin ring and controls the fidelity of cytokinesis. $J$. Cell. Sci. 129: 2613-2624

Barker SL, Lee L, Pierce BD, Maldonado-Báez L, Drubin DG \& Wendland B (2007) Interaction of the endocytic scaffold protein Pan1 with the type I myosins contributes to the late stages of endocytosis. Molecular Biology of the Cell 18: 2893-2903

Batters C, Arthur CP, Lin A, Porter J, Geeves MA, Milligan RA, Molloy JE \& Coluccio LM (2004) Myo1c is designed for the adaptation response in the inner ear. EMBO J. 23: 1433-1440

Bähler J, Wu JQ, Longtine MS, Shah NG, McKenzie A, Steever AB, Wach A, Philippsen P \& Pringle JR (1998) Heterologous modules for efficient and versatile PCR-based gene targeting in Schizosaccharomyces pombe. Yeast 14: 943-951

Bement WM \& Mooseker MS (1995) TEDS rule: a molecular rationale for differential regulation of myosins by phosphorylation of the heavy chain head. Cell Motil. Cytoskeleton 31: 87-92

Berro J \& Pollard TD (2014) Local and global analysis of endocytic patch dynamics in fission yeast using a new 'temporal superresolution' realignment method. Molecular Biology of the Cell 25: 3501-3514

Carbó N, Tarkowski N, Ipiña EP, Dawson SP \& Aguilar PS (2016) Sexual pheromone modulates the frequency of cytosolic Ca2+ bursts in Saccharomyces cerevisiae. Molecular Biology of the Cell 28: 501-510

Carpy A, Krug K, Graf S, Koch A, Popic S, Hauf S \& Macek B (2014) Absolute proteome and phosphoproteome dynamics during the cell cycle of Schizosaccharomyces pombe (Fission Yeast). Mol. Cell Proteomics 13: 1925-1936

Clos J \& Brandau S (1994) pJC20 and pJC40--two high-copy-number vectors for T7 RNA polymerase-dependent expression of recombinant genes in Escherichia coli. Protein Expression and Purification 5: 133-137 
Crivici A \& Ikura M (1995) Molecular and structural basis of target recognition by calmodulin. Annu Rev Biophys Biomol Struct 24: 85-116

East DA \& Mulvihill DP (2011) Regulation and function of the fission yeast myosins. J. Cell. Sci. 124: 1383-1390

Eastwood TA, Baker K, Brooker HR, Frank S \& Mulvihill DP (2017) An enhanced recombinant amino-terminal acetylation system and novel in vivohigh-throughput screen for molecules affecting a-synuclein oligomerisation. FEBS Letters 106: 8157-9

Egel R, Willer M, Kjaerulff S, Davey J \& Nielsen O (1994) Assessment of pheromone production and response in fission yeast by a halo test of induced sporulation. Yeast 10: 1347-1354

Geiser JR, van Tuinen D, Brockerhoff SE, Neff MM \& Davis TN (1991) Can calmodulin function without binding calcium? Cell 65: 949-959

Hayden SM, Wolenski JS \& Mooseker MS (1990) Binding of brush border myosin I to phospholipid vesicles. J. Cell Biol. 111: 443-451

Heissler SM \& Sellers JR (2016a) Various Themes of Myosin Regulation. Journal of Molecular Biology 428: 1927-1946

Heissler SM \& Sellers JR (2016b) Kinetic Adaptations of Myosins for Their Diverse Cellular Functions. Traffic 17: 839-859

lida H, Yagawa Y \& Anraku Y (1990) Essential role for induced Ca2+ influx followed by [Ca2+]i rise in maintaining viability of yeast cells late in the mating pheromone response pathway. A study of [Ca2+]i in single Saccharomyces cerevisiae cells with imaging of fura-2. J. Biol. Chem. 265: 13391-13399

Itadani A, Nakamura T \& Shimoda C (2007) Localization of type I myosin and $F$-actin to the leading edge region of the forespore membrane in Schizosaccharomyces pombe. Cell Struct. Funct. 31: 181-195

Itadani A, Nakamura T, Hirata A \& Shimoda C (2010) Schizosaccharomyces pombe Calmodulin, Cam1, Plays a Crucial Role in Sporulation by Recruiting and Stabilizing the Spindle Pole Body Components Responsible for Assembly of the Forespore Membrane. Eukaryotic Cell 9: 1925-1935

Jacinto E, Loewith R, Schmidt A, Lin S, Rüegg MA, Hall A \& Hall MN (2004) Mammalian TOR complex 2 controls the actin cytoskeleton and is rapamycin insensitive. Nat. Cell Biol. 6: 1122-1128

Kendrick-Jones J, Smith RC, Craig R \& Citi S (1987) Polymerization of vertebrate non-muscle and smooth muscle myosins. Journal of Molecular Biology 198: 241-252 
Laplante M \& Sabatini DM (2012) mTOR signaling in growth control and disease. Cell 149: 274-293

Lee S, Comer FI, Sasaki A, McLeod IX, Duong Y, Okumura K, Yates JR III, Parent CA \& Firtel RA (2005) TOR Complex 2 Integrates Cell Movement during Chemotaxis and Signal Relay in Dictyostelium. Molecular Biology of the Cell 16: 4572-4583

Lee WL, Bezanilla M \& Pollard TD (2000) Fission yeast myosin-I, Myo1p, stimulates actin assembly by Arp $2 / 3$ complex and shares functions with WASp. The Journal of Cell Biology 151: 789-800

Lewis JH, Greenberg MJ, Laakso JM, Shuman H \& Ostap EM (2012) Calcium regulation of Myosin-I tension sensing. Biophysical Journal 102: 2799_ 2807

Liu L \& Parent CA (2011) Review series: TOR kinase complexes and cell migration. The Journal of Cell Biology 194: 815-824

Lu Q, Li J, Ye F \& Zhang M (2014) Structure of myosin-1c tail bound to calmodulin provides insights into calcium-mediated conformational coupling. Nat Struct Mol Biol 22: 81-88

Ma Y, Sugiura R, Koike A, Ebina H, Sio SO \& Kuno T (2011) Transient Receptor Potential (TRP) and Cch1-Yam8 Channels Play Key Roles in the Regulation of Cytoplasmic Ca2+ in Fission Yeast. PLoS ONE 6: e22421

Maclver FH, Glover DM \& Hagan IM (2003) A 'marker switch' approach for targeted mutagenesis of genes in Schizosaccharomyces pombe. Yeast 20: $587-594$

Marguerat S, Schmidt A, Codlin S, Chen W, Aebersold R \& Bähler J (2012) Quantitative analysis of fission yeast transcriptomes and proteomes in proliferating and quiescent cells. Cell 151: 671-683

Marks J \& Hyams JS (1985) Localization of F-actin through the cell division cycle of Schizosaccharomyces pombe. European Journal of Cell Biology 39: $27-32$

Mashanov GI \& Molloy JE (2007) Automatic detection of single fluorophores in live cells. Biophysj 92: 2199-2211

Mashanov GI, Nobles M, Harmer SC, Molloy JE \& Tinker A (2010) Direct observation of individual KCNQ1 potassium channels reveals their distinctive diffusive behavior. J. Biol. Chem. 285: 3664-3675

Mashanov GI, Tacon D, Knight AE, Peckham M \& Molloy JE (2003) Visualizing single molecules inside living cells using total internal reflection fluorescence microscopy. 29: 142-152 
Mata J \& Bähler J (2006) Global roles of Ste11p, cell type, and pheromone in the control of gene expression during early sexual differentiation in fission yeast. Proc. Natl. Acad. Sci. U.S.A. 103: 15517-15522

Mata J, Lyne R, Burns G \& Bähler J (2002) The transcriptional program of meiosis and sporulation in fission yeast. Nat Genet 32: 143-147

Mentes A, Huehn A, Liu X, Zwolak A, Dominguez R, Shuman H, Ostap EM \& Sindelar CV (2018) High-resolution cryo-EM structures of actin-bound myosin states reveal the mechanism of myosin force sensing. Proceedings of the National Academy of Sciences 115: 1292-1297

Minc N, Boudaoud A \& Chang F (2009) Mechanical forces of fission yeast growth. Curr. Biol. 19: 1096-1101

Miseta A, Fu L, Kellermayer R, Buckley J \& Bedwell DM (1999) The Golgi apparatus plays a significant role in the maintenance of $\mathrm{Ca} 2+$ homeostasis in the vps33Delta vacuolar biogenesis mutant of Saccharomyces cerevisiae. J. Biol. Chem. 274: 5939-5947

Mitchison JM \& Nurse P (1985) Growth in cell length in the fission yeast Schizosaccharomyces pombe. J. Cell. Sci. 75: 357-376

Moreno S, Klar A \& Nurse P (1991) Molecular genetic analysis of fission yeast Schizosaccharomyces pombe. Meth. Enzymol. 194: 795-823

Moser MJ, Flory MR \& Davis TN (1997) Calmodulin localizes to the spindle pole body of Schizosaccharomyces pombe and performs an essential function in chromosome segregation. J. Cell. Sci. 110 ( Pt 15): 1805-1812

Moser MJ, Lee SY, Klevit RE \& Davis TN (1995) Ca2+ binding to calmodulin and its role in Schizosaccharomyces pombe as revealed by mutagenesis and NMR spectroscopy. J. Biol. Chem. 270: 20643-20652

Mund M, van der Beek JA, Deschamps J, Dmitrieff S, Hoess P, Monster JL, Picco A, Nedelec F, Kaksonen M \& Ries J (2018) Systematic Nanoscale Analysis of Endocytosis Links Efficient Vesicle Formation to Patterned Actin Nucleation. Cell 174: 1-13

Nguyen AW \& Daugherty PS (2005) Evolutionary optimization of fluorescent proteins for intracellular FRET. Nat Biotechnol 23: 355-360

O'Connell CB, Tyska MJ \& Mooseker MS (2007) Myosin at work: motor adaptations for a variety of cellular functions. Biochim. Biophys. Acta 1773: $615-630$

Palmer SE, Smaczynska-de Rooij II, Marklew CJ, Allwood EG, Mishra R, Johnson S, Goldberg MW \& Ayscough KR (2015) A dynamin-actin interaction is required for vesicle scission during endocytosis in yeast. Curr. Biol. 25: 868-878 
Pasapera AM, Plotnikov SV, Fischer RS, Case LB, Egelhoff TT \& Waterman CM (2015) Rac1-dependent phosphorylation and focal adhesion recruitment of myosin IIA regulates migration and mechanosensing. Curr. Biol. 25: 175-186

Pearce LR, Komander D \& Alessi DR (2010) The nuts and bolts of AGC protein kinases. Nat Rev Mol Cell Biol 11: 9-22

Petersen J (2009) TOR signalling regulates mitotic commitment through stress-activated MAPK and Polo kinase in response to nutrient stress. Biochem. Soc. Trans 37: 273-277 Available at: http://eutils.ncbi.nlm.nih.gov/entrez/eutils/elink.fcgi?dbfrom=pubmed\&id=1 9143645\&retmode=ref\&cmd=prlinks

Petersen J \& Nurse P (2007) TOR signalling regulates mitotic commitment through the stress MAP kinase pathway and the Polo and Cdc2 kinases. Nature Publishing Group 9: 1263-1272

Picco A, Mund M, Ries J, Nedelec F \& Kaksonen M (2015) Visualizing the functional architecture of the endocytic machinery. eLife 4:

Redowicz MJ (2001) Regulation of nonmuscle myosins by heavy chain phosphorylation. J. Muscle Res. Cell. Motil. 22: 163-173

Rogers SL, Karcher RL, Roland JT, Minin AA, Steffen W \& Gelfand VI (1999) Regulation of melanosome movement in the cell cycle by reversible association with myosin V. The Journal of Cell Biology 146: 1265-1276

Sammons MR, James ML, Clayton JE, Sladewski TE, Sirotkin V \& Lord M (2011) A calmodulin-related light chain from fission yeast that functions with myosin-I and PI 4-kinase. J. Cell. Sci. 124: 2466-2477

Sirotkin V, Beltzner CC, Marchand J-B \& Pollard TD (2005) Interactions of WASp, myosin-I, and verprolin with Arp2/3 complex during actin patch assembly in fission yeast. The Journal of Cell Biology 170: 637-648

Sirotkin V, Berro J, Macmillan K, Zhao L \& Pollard TD (2010) Quantitative analysis of the mechanism of endocytic actin patch assembly and disassembly in fission yeast. Molecular Biology of the Cell 21: 2894-2904

Suizu T, Tsutsumi H, Kawado A, Suginami K, Imayasu S \& Murata K (1995) Calcium ion influx during sporulation in the yeast Saccharomyces cerevisiae. Can. J. Microbiol. 41: 1035-1037

Sun Y, Leong NT, Wong T \& Drubin DG (2015) A Pan1/End3/Sla1 complex links Arp2/3-mediated actin assembly to sites of clathrin-mediated endocytosis. Molecular Biology of the Cell 26: 3841-3856

Sun Y, Martin AC \& Drubin DG (2006) Endocytic Internalization in Budding Yeast Requires Coordinated Actin Nucleation and Myosin Motor Activity. Developmental Cell 11: 33-46 
Takeda T \& Yamamoto M (1987) Analysis and in vivo disruption of the gene coding for calmodulin in Schizosaccharomyces pombe. Proc. Natl. Acad. Sci. U.S.A. 84: 3580-3584

Toya M, Motegi F, Nakano K, Mabuchi I \& Yamamoto M (2001) Identification and functional analysis of the gene for type I myosin in fission yeast. Genes Cells 6: 187-199

Trybus KM, Gushchin MI, Lui H, Hazelwood L, Krementsova EB, Volkmann N \& Hanein D (2007) Effect of calcium on calmodulin bound to the IQ motifs of myosin V. J. Biol. Chem. 282: 23316-23325

Tsien RY (1980) New calcium indicators and buffers with high selectivity against magnesium and protons: design, synthesis, and properties of prototype structures. Biochemistry 19: 2396-2404

Wilson-Grady JT, Villén J \& Gygi SP (2008) Phosphoproteome analysis of fission yeast. J. Proteome Res. 7: 1088-1097

Win TZ, Mulvihill DP \& Hyams JS (2002) Take five: a myosin class act in fission yeast. Cell Motil. Cytoskeleton 51: 53-56 
893

894

895

896

897

898

899

900

901

902

903

904

905

906

907

908

909

910

911

912

913

914

915

916

917

918

919

920

921

922

923

924

\section{Figure Legends}

Figure 1. Myo1 serine 742 phosphorylation is TORC2 dependent. (A) Anti-

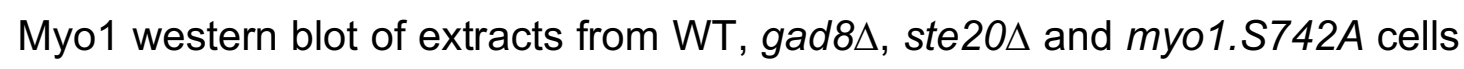
separated using Phos-Tag SDS-PAGE reveals Myo1 is subject to multiple phosphorylation events $\left(^{*}\right)$. (B) Sequence alignment of myosin $I Q$ regions shows Myo1 ${ }^{\mathrm{S742}}$ lies within an AGC consensus sequence, conserved in class I and $\mathrm{V}$ myosins. (C) Western blots of extracts from myo1 ${ }^{+}$and myo1-S742A cells stained with Ponceau $S$ and probed with phospho-specific anti-Myo ${ }^{S 742}$ antibodies demonstrate antigen specificity. (D) Myo $1^{\mathrm{S} 742}$ is not phosphorylated in ste20 cells lacking the fission yeast TORC2 regulator Rictor ${ }^{S t e 20}$. (E) Myo1 ${ }^{\mathrm{S} 742}$ is phosphorylated in cells cultured in minimal media containing Glutamic acid (EMMG) but not in EMM2 with an ammonium chloride nitrogen source. (F) WT and myo1.S742A cells grown to starvation in EMMG for $72 \mathrm{hrs}$. In contrast to WT, myo1.S742A cells fail to stop growing upon media induced G1 arrest. Scale $-5 \mu \mathrm{m}$.

Figure 2. In vitro characterisation of interactions between Myo1 and Cam1. (A) Predicted models of the CyPet-Cam1-YPet FRET reporter protein (Cam1-FRET) in the absence (upper panel) and presence (lower panel) of $\mathrm{Ca}^{2+}$. (B) pCa curve plotting $\mathrm{Ca}^{2+}$ dependent changes of Cam1-FRET protein conformation ( $\Delta$ in FRET signal). (C) pCa curve plotting $\mathrm{Ca}^{2+}$ dependent changes in IAANS fluorescence of IAANS labelled Cam1-T6C. (D) Transient curves of changes in Quin2 fluorescence brought by $\mathrm{Ca}^{2+}$ release from Cam1 (black) and Cam2 (red). (E) Predicted models of the CyPet-Myo1 ${ }^{1 \mathrm{Q} 12}$-YPet FRET reporter protein (Myo1IQ12-FRET) in the absence (upper panel) or presence (lower panel) of Calmodulin binding. (F) Spectra of Myo1 1Q12-FRET reporter alone (black line) or with Cam1 in the presence $\mathrm{Ca}^{2+}$ (red dotted line) or absence (grey dotted line) of $\mathrm{Ca}^{2+}$. (G) Curves plotting Cam1 dependent changes of FRET donor signal of wild type (black) or S742D phosphomimetic (blue) Myo1 1Q12-FRET proteins. (H) Spectra of Myo1 1Q12-FRET (black traces) and Myo1 ${ }^{\text {IQ12-S742D }}$-FRET (blue traces) in the absence (dashed lines) or presence (lines lines) of Cam1 illustrate differences in conformation of the Myo1 neck region. (I) pCa curve plotting $\mathrm{Ca}^{2+}$ dependent changes in acceptor 
925 fluorescence of Myo1 1Q12-FRET. (J) Curves plotting Cam1 (black) and Cam2

926 (red) dependent changes of FRET donor signal of Myo1-FRET proteins

927 containing single IQ domains (IQ1 - empty shapes; IQ2 - filled shapes).

928 Figure 3. Myo1 and Cam1 dynamics in wild type and myo1.S742A cells.

929 (A) Maximum projections of 31-z stack widefield images of mNG.myo1, 930 cam1.gfp and cam2.gfp cells (Scales - $5 \mu \mathrm{m}$ ). (B) An example relative intensity 931 trace of a mNeongreen.Myo1 endocytic event. Linear fitting (60 points) was 932 used to find the highest slope for both rising and falling edges. The intercept 933 with zero intensity level was used to calculate $T_{\text {begin, }} T_{\text {end }}$, and subsequently the 934 duration of the event. Insert: An arrow shows the location of the endocytosis 935 event (5X5 pixels area). (C) Averaged profile from 50 individual Myo1 936 membrane association events described in (B), synchronised relative to $T_{\text {begin }}$ 937 (grey line) and $\mathrm{T}_{\text {end }}$ (black line). (D) Plot of event duration (sec) against number 938 of Myo1 molecules (fluorescence amplitude). (E) Averaged profile from 52 939 individual Cam1 membrane association events from TIRFM timelapse analysis 940 of cam1.gfp cells. (F) Example of fluorescence trace from simultaneously 941 tracking Myo1 and Cam1 membrane binding and disassociation events from 942 TIRFM timelapse analysis of mNeongreen.myo1 cam1.mCherry cells. (G) 943 Averaged profiles of combined averages of individual Myo1 (black line and grey 944 s.d.) and Myo1.S742A (grey line) membrane association events from TIRFM 945 timelapse analysis of $m$ Neongreen.myo1 and mNeongreen.myo1.S742A cells 946 respectively. (H) Analysis of mean duration of Myo1 and Cam1 endocytic 947 events in wt and myo1.S742A cells from widefield imaging ( $\mathrm{r}>30)$. Asterisks 948 denote differences with $>99 \%$ confidence. (I) Analysis of mean LifeACT and 949 Cam2 signal at endocytic foci in WT and myo1.S742A cells $(n>30)$. No 950 differences observed at $95 \%$ level of confidence. All error bars - s.d.

951 Figure 4. Myo1 $\mathbf{S 7 4 2}$ is phosphorylated in a cell cycle dependent manner 952 to affect polarised growth. (A) Actin foci periodicity at ends of WT and 953 myo1.S742A cells in $\mathrm{G} 2$ phase $(n>30)$. Asterisks denote difference with $>99 \%$ 954 confidence. (B) Graphic highlighting Cdc10 and Cdc25 execution points in 955 relation to cell cycle phases and periods of monopolar / bipolar growth (left). 956 Myo1 ${ }^{\mathrm{S742}}$ is phosphorylated in cdc10.v50 arrested $\mathrm{G}_{1}$ cells, but not in pre-mitotic 
$957 \mathrm{G}_{2}$ cdc25.22 arrested cells (right panels). (C) Averaged growth curves from 3 958 independent experiments of prototroph WT (empty circles) and myo1.S742A 959 (grey filled circles) cells cultured in EMMG at $34^{\circ} \mathrm{C}$. Error bars - s.d. (D) Myosin9601 distribution and cell morphology of prototroph $m$ Neongreen.myo ${ }^{+}$and 961 mNeongreen.myo1.S742A cells cultured in EMMG at $34^{\circ} \mathrm{C}$. Asterisks highlight 962 long bent cells. Scale - $10 \mu \mathrm{m}$. (E) Calcofluor stained WT and myo1.S742A 963 cells. Asterisks highlight long bent cells displaying monopolar growth. Scale - 5 $964 \mu \mathrm{m}$. (F) Ratio Sla2-mCherry fluorescence at "new": "old" cell end, averaged 965 from >30 growing mid-log sla2-mCherry myo ${ }^{+}$(upper panel) and sla2-mCherry 966 myo1.S742A (lower panel) cells. Boxes plot median and quartile for each length 967 measured, lines are plotted from the mean average value at each length 968 measured.

969 Figure 5. Cam2 associates with internalised endocytic vesicles. (A) 970 Kymographs of GFP labelled foci from maximum projections of $13-z$ plane 971 timelapse images of mNeongreen.myo1 (upper panel), cam1.gfp (middle 972 panel) and cam2.gfp (bottom panel) cells. Myo1 and Cam1 endocytic foci did 973 not move on the membrane (black arrows). Spindle Pole Body (asterisk) and 974 myosin V (white arrow) associated Cam1 are highlighted. In contrast Cam2 foci 975 displayed extensive lateral movements. (B) Kymographs generated from single 976 z-plane timelapse images of single endocytic foci surface during vesicle 977 formation and subsequent internalisation. While Myo1 and Cam1 only 978 associate with the plasma membrane, Cam2, Sla2 and actin are internalised 979 on the vesicle after scission. (C) Kymographs of Cam2 and Sla2 co980 internalisation in sla2.mCherry cam2.gfp cells. (D) Maximum projection of 31-z 981 slice image of cam1.mCherry cam2.gfp cells reveals Cam1 (magenta) and 982 Cam2 (green) colocalise to a subset of endocytic foci. (E-G) Single frames (left 983 panels) and time kymographs (right panels) from maximum projections of $13-z$ 984 plane timelapse images of cam1.gfp (E), cam2.gfp (F) and LifeACT.mCherry 985 (G) in either myo1 $^{+}$(upper panels) or myo1s (lower panels) cells show only 986 Cam1 endocytic foci recruitment is dependent upon Myo1. Myo1 is required for 987 internalisation of Cam2-GFP and LifeACT.mCherry labelled foci. Scales - $5 \mu \mathrm{m}$.

988 Figure 6. Cam2 impacts endosome organisation. (A) An example of the 
989

990

991

fluorescence trace of Cam2 membrane binding and vesicle internalisation event from TIRFM analysis of cam2.gfp cells. An abrupt drop in the fluorescence was marked as "scission time" (grey vertical line). An arrow shows the location of the monitored endocytic event (5X5 pixels area). (B) Averaged profile from 32 individual Cam2 membrane association events (green line) described in (A), together with Cam1-mCherry profile (red) from two-colour TIRFM imaging of cam1.mCherry cam2.gfp cells. Events were synchronized relative Cam1 $\mathrm{T}_{\text {begin }}$ Dashed line denotes mean timing of vesicle scission. $(\mathrm{C})$ Maximum projection of $31-z$ slice widefield image of a mixture of prototroph yfp.myo1 sid4.tdTomato and yfp.myo1 cam2s cells. (D) Maximum projection of 31-z slice widefield image of a mixture of prototroph cam1.gfp sid4.tdTomato and cam1.gfp cam2 (arrows) cells. (E) Magnification of TIRF heat map of endocytic Cam1 in cam2 ${ }^{+}$(upper panel) and cam2s (lower panel) cells. Squares correspond to regions extending outward from centre of focus. (F) Plot of mean distribution of Cam1 across > 40 endocytic sites in WT and cam2A cells. (G) Curves plotting Cam2 dependent changes of FRET donor signal of

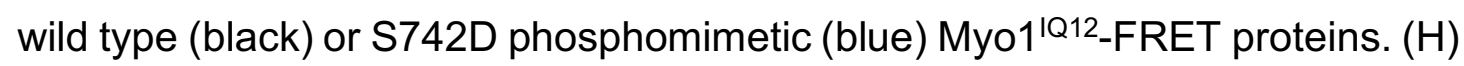
Spectra of Myo1 ${ }^{\mathrm{IQ} 12}$-FRET reporter alone (black line), with Cam2 in the presence $\mathrm{Ca}^{2+}$ (grey solid line) or absence (grey dotted line) of $\mathrm{Ca}^{2+}$, or with Cam1 in the absence of $\mathrm{Ca}^{2+}$ (black dotted line). Scales $-5 \mu \mathrm{m}$.

\section{Figure 7. Myo1 $\mathbf{S 7 4 2}$ phosphorylation regulated Cam1 and Cam2} dynamics during meiosis. (A) Kymographs of Cam2.GFP foci dynamics in myo1 $^{+}$(upper panel) and myo1.S742A (lower panel) cells. (B) Scheme of consequence of phosphorylation of Myo1 Ser742 (small empty circle) and $\mathrm{Ca}^{2+}$ levels upon Cam1 (light grey filled circle) and Cam2 (dark grey filled circle) binding to the IQ1 (solid thick black line) and IQ2 (compound line) motifs of Myo1, and impact on relative orientation of the myosin lever arm (dashed arrow). Highlighted combination of unphosphorylated Myo $1^{\mathrm{S} 742} \& \mathrm{Ca}^{2+}$ does not normally occur in wild type cells. (C) Western blots of extracts from G1 arrested cdc10.v50 myo1 $^{+}$, cdc10.v50 myo1-S742A cells, conjugation arrested fus1A cells or spores, probed with phospho-specific anti-Myo1 ${ }^{\mathrm{S742}}$ antibodies confirm Myo1S742 remains phosphorylated throughout the sexual cycle. (D) Maximum projection of 13-z slice GFP fluorescence image and transmitted light image 
1022 from a timelapse of vegetative (cell 1) and meiotic (cell 2) gfp-act1 cells. Image

1023 from a GFP-act signal. Kymographs in the right panels were generated along

1024 the two dotted axes. (E) Histograms of lifetimes of Myo1 (black bars), Cam1

1025 (white bars) and Cam2 (grey bars) foci in vegetative (left panel) and meiotic

1026 (right panel) cells. (F) Lifetimes of Myo1, Cam1 and Cam2 foci in WT (white

1027 bars) and myo1.S742A (black bars) meiotic cells. (G) Micrographs of 1028 myo1.S742A cell morphology on starvation media. * highlight cells with growth 1029 and polarity defects; arrows highlight cells with elongated or abnormally bent 1030 shmooing tips; and arrow heads highlight meioses resulting in defective spore 1031 formation. Scales $-5 \mu \mathrm{m}$.

1032 Figure 8. Model of Myo1 tension dependent interactions at the plasma 1033 membrane. (A) Myo1 (green) transiently associates with the plasma

1034 membrane. (B) In the presence of early markers of endocytosis (blue) this 1035 interaction is stabilised, and Myo1 accumulates to a critical concentration at the 1036 endocytic foci (C), whereupon myosin heads associate with growing Arp2/3 1037 (purple) nucleated actin polymers (yellow) attached to the membrane (D), and 1038 monitor tension between the actin filament and internalised plasma membrane 1039 (E). Upon release of the calmodulin light chain (red), the myosin-1 would its 1040 ability to monitor tension and subsequently disengage from the actin polymer 1041 and membrane $(F)$. 
1043

1044

1045

1046

1047

1048

1049

1050

1051

1052

1053

1054

1055

1056

1057

1058

1059

1060

1061

1062

1063

1064

1065

1066

1067

1068

1069

1070

1071

1072

1073

\section{Supplementary Data Legends}

Supplementary Figure 1. Purified proteins used during in vitro studies. Coomassie stained SDS-PAGE gel of recombinant proteins expressed and purified during this study. From left to right lanes contain $(\mathrm{L})$ protein standard; (1) Nt-acetylated Cam1; (2) Nt-acetylated Cam1-T6C; (3) Cam1-FRET; (4) Cam2; (5) IQ12 peptide (not used during this study); (6) Myo1IQ12-FRET; and (7) Myo1IQ12S742D-FRET.

Supplementary Figure 2. Relative TIRF profiles. Combined profiles of averages from TIRFM timelapse analysis of Myo1 and Cam1 dynamics in wild type or myo1.S742A strains. (A) Myo1 (blue) and Cam1 (red) membrane association in wild type cells. (B) Myo1 membrane association in wild type (blue) and myo1.S742A (red) cells. (C) Myo1 (blue) and Cam1 (red) membrane association in myo1.S742A cells. (D) Cam1 membrane association in wild type (blue) and myo1.S742A (red) cells.

\section{Supplementary Figure 3. Myo $1^{\mathrm{S742}}$ phosphorylation fluctuates in a cell} cycle dependent manner. A cdc10.v50 culture was synchronized in G1 by shifting to $36^{\circ} \mathrm{C}$ for $240 \mathrm{~min}$ before returning to $25^{\circ} \mathrm{C}$ at time 0 . Samples of cells were taken every 20 minutes from the release and processed for western blotting to monitor of Myo1 ${ }^{\text {S742 }}$ phosphorylation (A). The membrane was subsequently probed with anti-Myo1 antibodies (B) to monitor total Myo1. Equal loading was monitored by Ponceau staining of the membrane. (C) Densitometry measurements of the bands in these blots are plotted along with the \% of cells in the culture with septa.

Supplementary Figure 4. Cam1 and Cam2 do not interact directly. (A) Overlaid OD280 spectra were recorded from eluate from a Superdex 75 gel filtration column which had been loaded with either Cam1 (grey line), Cam2 (black line) or Cam1 and Cam2 (red line) under identical 4 mM EGTA buffer conditions. (B) Maximum IAANS fluorescence values (440 nm) of $0.5 \mu \mathrm{M}$ Cam1-IAANS at a range of $\mathrm{pCa}$ values. Black symbols show values of Cam1IAANS, red symbols show values of Cam1-IAANS with $5 \mu \mathrm{M}$ Cam2 protein. 2 $\mathrm{mM}$ Ca- EGTA buffers were used to give indicated $\mathrm{pCa}$ values. $\mathrm{pCa50}$ values 
1074

1075

1076

1077

1078

1079

1080

1081

1082

1083

1084

1085

1086

1087

1088

1089

1090

1091

1092

1093

1094

1095

1096

1097

1098

1099

1100

1101

1102

calculated from Origin fitting analysis - Hill equation.

\section{Supplementary Figure 5. Multiple labelling strategies for Myo1, Cam1 and} Cam2 disrupts normal distribution. Cam1 has increased cytoplasmic signal and reduced signal at endocytic foci in cells expressing both cam1.gfp and mCherry.myo1 (A (GFP-green, mCherry-magenta)) compared to cells expressing cam1.gfp alone (B). Similarly, Cam1 has increased cytoplasmic signal and reduced relative signal at endocytic foci in CFP-myo1 cam1.mCherry cells (C). (D) Growth curves of prototroph cam1.gfp (green) and cam1.gfp $m$ Cherry.myo 1 cells cultured in EMMG at $25^{\circ} \mathrm{C}$. (E) Cam1 (green) localisation is disrupted in cam1.gfp cam2.mCherry cells, with less Cam1 on endocytic foci, and localising to the mitotic spindle which is never observed in cells expressing FP labelled Cam1 alone.

Supplementary Movie 1: Timelapse of TIRFM imaged mNeongreen.myo1 cells showing rapid single molecule interactions of Myo1 at the plasma membrane. Frame Rate: $15 \mathrm{msec} /$ frame.

Supplementary Movie 2: Timelapse of TIRFM imaged mNeongreen.myo1 cells showing endocytosis associated interactions of Myo1 at the plasma membrane. Frame rate: $50 \mathrm{msec} /$ frame.

Supplementary Movie 3: Timelapse of TIRFM imaged cam2.gfp cells showing Cam2 recruiting to endocytic vesicles, to which it remains associated after scission and internalisation of the endosome. Frame rate: $50 \mathrm{msec} /$ frame.

Supplementary Movie 4: Timelapse of TIRFM imaged cam1.mCherry cam2.gfp cells showing early recruitment of Cam1 (red) subsequent recruitment of Cam2 (green) to sites of endocytosis. Cam1 disassociates prior to vesicle scission, while Cam2 remains associated with the internalised endosome. Frame rate: $50 \mathrm{msec} /$ frame.

Supplementary Movie 5: Timelapse of maximum projections from 13-z slice widefield images of $m$ Neongreen.myo1 cells showing typical examples of Myo1 dynamics in vegetative and meiotic cells. Frame rate: $650 \mathrm{msec} /$ frame. 
1103 Supplementary Movie 6: Timelapse of maximum projections from 13-z slice

1104 widefield images of cam1.gfp cells showing typical examples of Cam1

1105 dynamics in vegetative and meiotic cells. Frame rate: $650 \mathrm{msec} /$ frame.

1106 Supplementary Movie 7: Timelapse of maximum projections from 13-z slice

1107 widefield images of cam2.gfp cells showing typical examples of Cam2

1108 dynamics in vegetative and meiotic cells. Frame rate: $650 \mathrm{msec} / \mathrm{frame}$.

1109 Supplementary Movie 8: Timelapse of maximum projections from 13-z slice

1110 widefield images of gfp.act1 cells showing typical examples of Act1 dynamics

1111 in vegetative and meiotic cells. Frame rate: $650 \mathrm{msec} /$ frame.

1112 Supplementary Table 1: Strains used during this study.

1113 Supplementary Table 2: Oligonucleotides used during this study. 
bioRxiv preprint doi: https://doi.org/10.1101/498865; this version posted December 18,2018 . The copyright holder for this preprint (which was not certified by peer review) is the author/funder, who has granted bioRxiv a license to display the preprint in perpetuity. It is made available under aCC-BY 4.0 International license.

\begin{tabular}{|c|c|c|c|c|}
\hline Myo1 & mNeonGreen-myo1 & $\begin{array}{c}\text { mNeonGreen- } \\
\text { myo1-S742A }\end{array}$ & 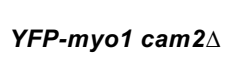 & - \\
\hline Whole cell fluorescence (AU) & $9,453,813$ & $0.86(0.8628)$ & $0.90(0.0295)$ & - \\
\hline Cell size $\left(\mu m^{2}\right)$ & 98.9 & $\mathbf{0 . 8 4}(0.0863)$ & $0.95(0.4542)$ & - \\
\hline Maximum intensity $(\mathrm{AU})$ & 33,477 & $0.92(0.1446)$ & $0.62(0.0001)$ & - \\
\hline Number of foci & 15.9 & $0.82(0.0203)$ & $0.84(0.0261)$ & - \\
\hline Average foci volume $\left(\mu \mathrm{m}^{3}\right)$ & 0.98 & $0.98(0.8595)$ & $0.64(0.0001)$ & - \\
\hline Total foci volume $\left(\mu \mathrm{m}^{3}\right)$ & 15.2 & $0.75(0.0020)$ & $0.53(0.0001)$ & - \\
\hline Total foci fluorescence (AU) & 139,712 & $0.76(0.0061)$ & $0.45(0.0001)$ & - \\
\hline Average foci lifetime (s) & 14.0 & $10.9(0.0001)$ & ND & - \\
\hline$N=$ & 32 & 30 & 37 & - \\
\hline Cam1 & $\begin{array}{c}\text { cam1-gfp } \\
\left(\mathrm{myo1}^{+}\right)\end{array}$ & $\begin{array}{c}\text { cam1-gfp myo1- } \\
\text { s742A }\end{array}$ & cam1-gfp cam 2 $\Delta$ & cam1-gfp myo1 $\Delta$ \\
\hline Whole cell fluorescence (AU) & $61,530,900$ & $0.89(0.0197)$ & $0.97(0.7145)$ & $1.14(0.0733)$ \\
\hline Cell size $\left(\mu m^{2}\right)$ & 86.1 & $0.99(0.9271)$ & $1.08(0.2016)$ & $1.00(0.9748)$ \\
\hline Maximum intensity (AU) & 251,700 & $0.82(0.0563)$ & $0.72(0.0001)$ & $1.41(0.0001)$ \\
\hline Number of foci & 14.1 & $0.96(0.6960)$ & $0.93(0.3200)$ & $0.42(0.0001)$ \\
\hline Average foci volume $\left(\mu \mathrm{m}^{3}\right)$ & 1.12 & $0.67(0.0081)$ & $0.74(0.0321)$ & $1.52(0.0188)$ \\
\hline Total foci volume $\left(\mu \mathrm{m}^{3}\right)$ & 14.33 & $0.68(0.0004)$ & $0.78(0.0703)$ & $0.56(0.0001)$ \\
\hline Total foci fluorescence (AU) & $1,020,350$ & $0.63(0.0002)$ & $0.66(0.0013)$ & $0.60(0.0001)$ \\
\hline Average foci lifetime (s) & 10.4 & $9.4(0.0001)$ & $13.3(0.0001)$ & - \\
\hline $\mathrm{N}=$ & 25 & 15 & 56 & 27 \\
\hline Cam2 & $\begin{array}{c}\text { cam 2-gfp } \\
\left(\mathrm{myo1}^{+}\right)\end{array}$ & $\begin{array}{c}\text { cam2-gfp myo1- } \\
\text { S742A }\end{array}$ & - & cam2-gfp myo1 $\Delta$ \\
\hline Whole cell fluorescence (AU) & $39,259,937$ & $1.01(0.8063)$ & - & $1.48(0.0001)$ \\
\hline Cell size $\left(\mu m^{2}\right)$ & 79.3 & $0.89(0.2385)$ & - & $1.15(0.3114)$ \\
\hline Maximum intensity $(\mathrm{AU})$ & 267,547 & $0.98(0.6339)$ & - & $0.78(0.0001)$ \\
\hline Number of foci & 20.8 & $0.94(0.4155)$ & - & $1.26(0.0048)$ \\
\hline Average foci volume $\left(\mu \mathrm{m}^{3}\right)$ & 0.82 & $1.11(0.0737)$ & - & $1.63(0.0001)$ \\
\hline Total foci volume $\left(\mu \mathrm{m}^{3}\right)$ & 16.53 & $1.05(0.4287)$ & - & $2.10(0.0001)$ \\
\hline Total foci fluorescence (AU) & 859,161 & $1.06(0.3374)$ & - & $1.82(0.0001)$ \\
\hline$N=$ & 20 & 31 & - & 17 \\
\hline LifeAct & $\begin{array}{l}\text { LifeAct } \\
\left(\text { myo1 }^{+}\right)\end{array}$ & LifeAct myo1-S742A & ND & LifeAct myo1 $\Delta$ \\
\hline Whole cell fluorescence (AU) & $17,116,300$ & $1.14(0.0936)$ & - & $1.15(0.2851)$ \\
\hline Cell size $\left(\mu \mathrm{m}^{2}\right)$ & 84.5 & $1.01(0.8787)$ & - & $1.14(0.1529)$ \\
\hline Maximum intensity $(\mathrm{AU})$ & 94,671 & $1.06(0.4403)$ & - & $0.64(0.016)$ \\
\hline Number of foci & 19.8 & $0.94(0.5502)$ & - & $1.22(0.0147)$ \\
\hline Average foci volume $\left(\mu \mathrm{m}^{3}\right)$ & 0.73 & $1.19(0.0346)$ & - & $0.95(0.6822)$ \\
\hline Total foci volume $\left(\mu \mathrm{m}^{3}\right)$ & 13.96 & $1.15(0.1771)$ & - & $1.14(0.2759)$ \\
\hline Total foci fluorescence (AU) & 327,017 & $1.18(0.1832)$ & - & $1.03(0.8674)$ \\
\hline $\mathrm{N}=$ & 23 & 23 & - & 23 \\
\hline
\end{tabular}

Table 1:

AutoQuantX3 Image analysis data of wide-field fluorescence data of cells. Mutant strains were imaged in mix experiments with wild type cells, analysis for these cells is shown relative to the wild type control cells for each experiment. Statistical significance determined by an unpaired $t$-test is shown in brackets, a statistical significance of $p<0.05$ is indicated in red. 
bioRxiv preprint doi: https://doi.org/10.1101/498865; this version posted December 18,2018 . The copyright holder for this preprint (which was not certified by peer review) is the author/funder, who has granted bioRxiv a license to display the preprint in perpetuity. It is made available under aCC-BY 4.0 International license.

\begin{tabular}{|l|c|c|c|c|c|}
\hline Protein (myo1 allele) & $\begin{array}{c}\text { Duration } \\
\text { (SEM) }\end{array}$ & $\begin{array}{c}\text { Amplitude } \\
\text { (SEM) }\end{array}$ & $\begin{array}{c}\text { Rise rate } \\
\text { (SEM) }\end{array}$ & $\begin{array}{c}\text { Drop rate } \\
\text { (SEM) }\end{array}$ & N \\
\hline Myo1 $\left(\right.$ myo1 $\left.^{+}\right)$ & $13.84(0.39)^{1,2,3}$ & $2373(155)$ & $536(40.4)$ & $567(43)$ & 50 \\
Cam1 $\left(\right.$ myo1 $\left.^{+}\right)$ & $10.99(0.21)^{1}$ & $4539(292)$ & $1074(83)$ & $1028(69)$ & 52 \\
Myo1 (myo1.S742A) & $12.28(0.31)^{2,4}$ & $2274(128)$ & $536(34)$ & $570(41)$ & 67 \\
Cam1 (myo1.S742A) & $12.15(0.38)^{3,4}$ & $4629(301)$ & $1153(98)$ & $1031(77)$ & 43 \\
\hline
\end{tabular}

Significance differences observed in durations of: ${ }^{1}$ Myo1 (wt cells) and Cam1 (wt cells) foci $p<0.0001 ;{ }^{2}$ Myo1 (wt cells) and Myo1 (myo1.S742A cells) foci $p<0.002 ;{ }^{3}$ Myo1 (wt cells) and Cam1 (myo1.S742A cells) foci $p<0.0064$.

${ }^{4}$ No significant difference observed between duration of Myo1 (my01.S742A cells) and Cam1 (myo1.S742A cells) foci $p<0.79$.

Table 2:

Image analysis data of TIRF data of cells of the indicated genotype. 
Figure 1

A
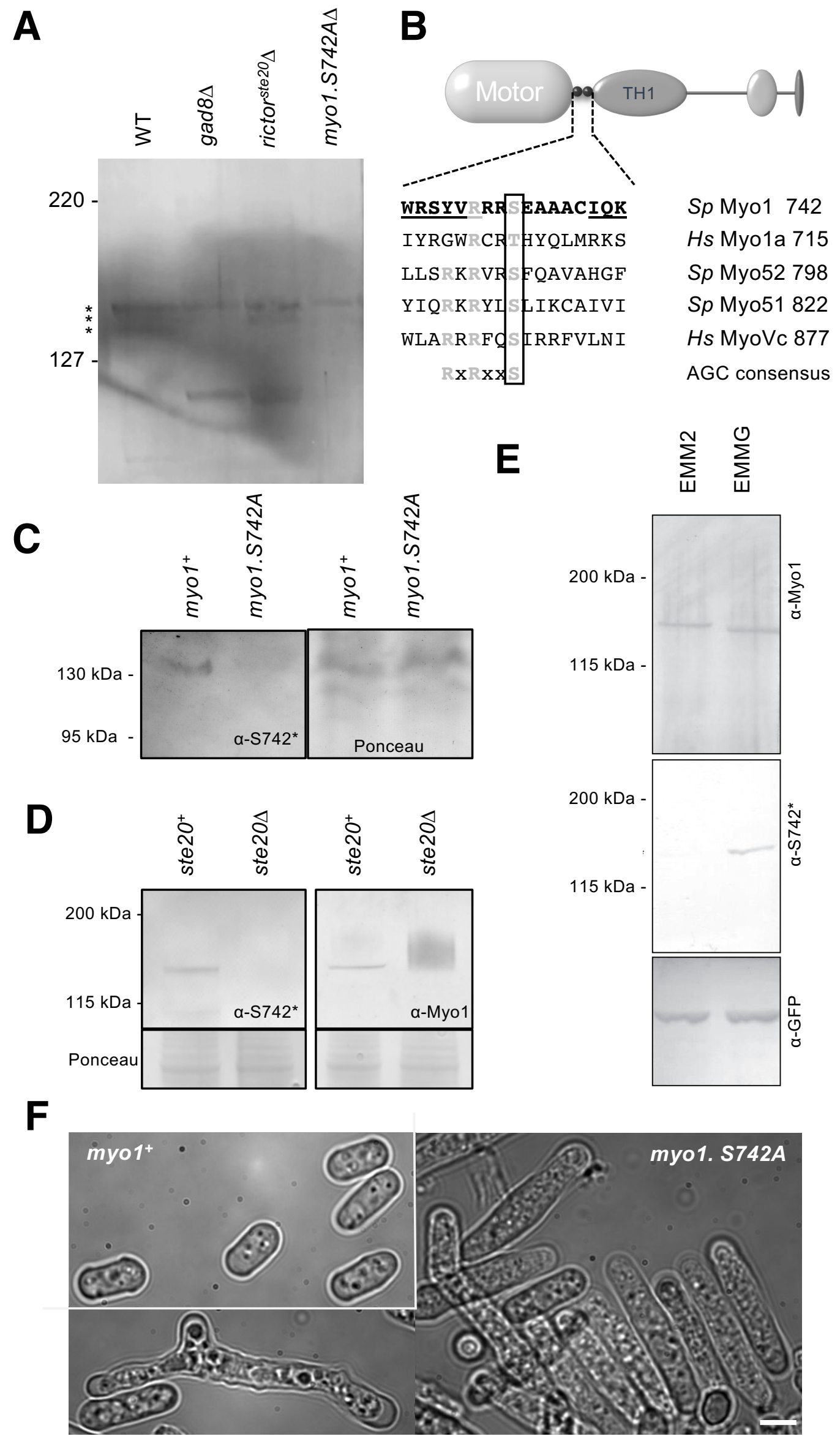


\section{Figure 2}
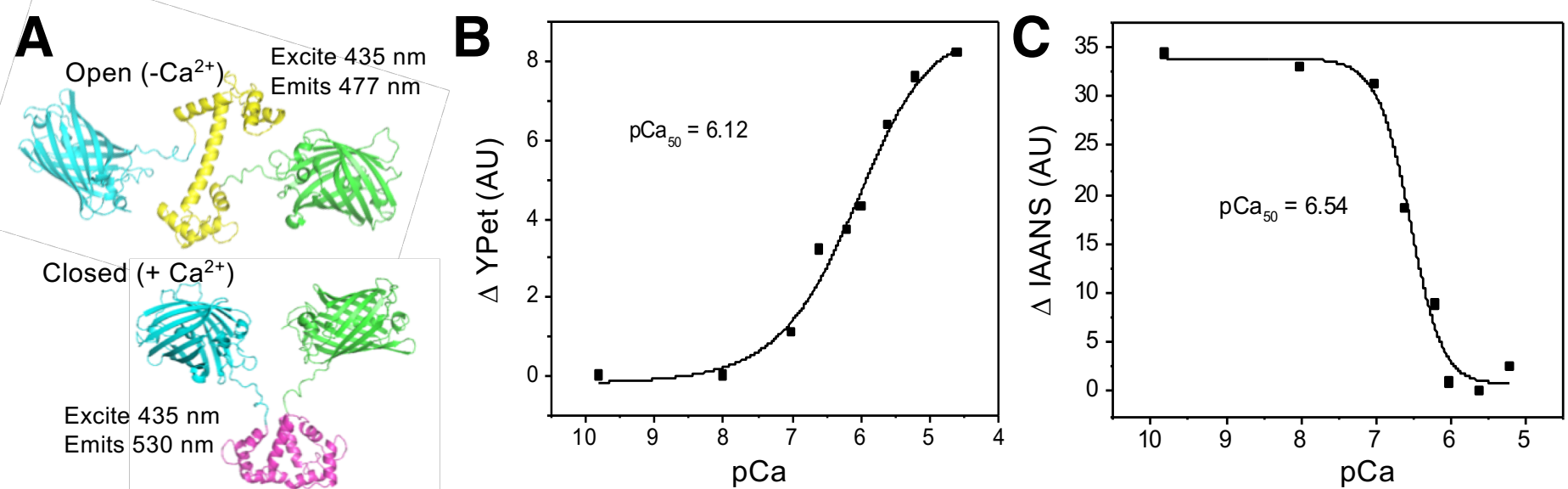

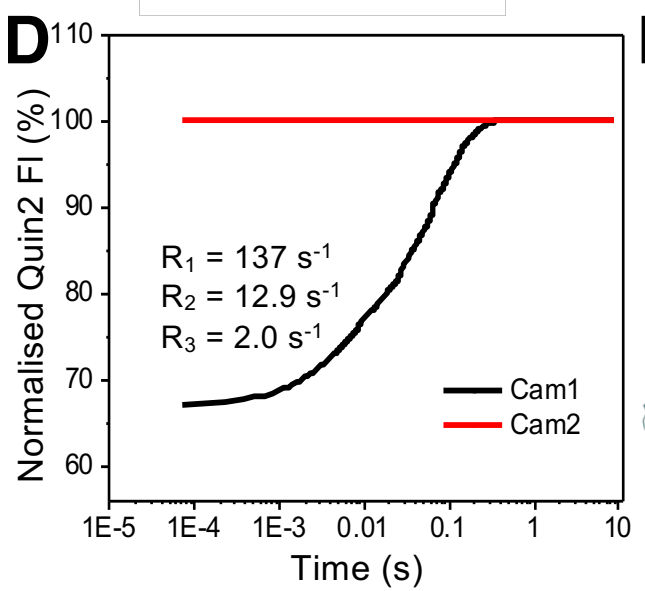

G
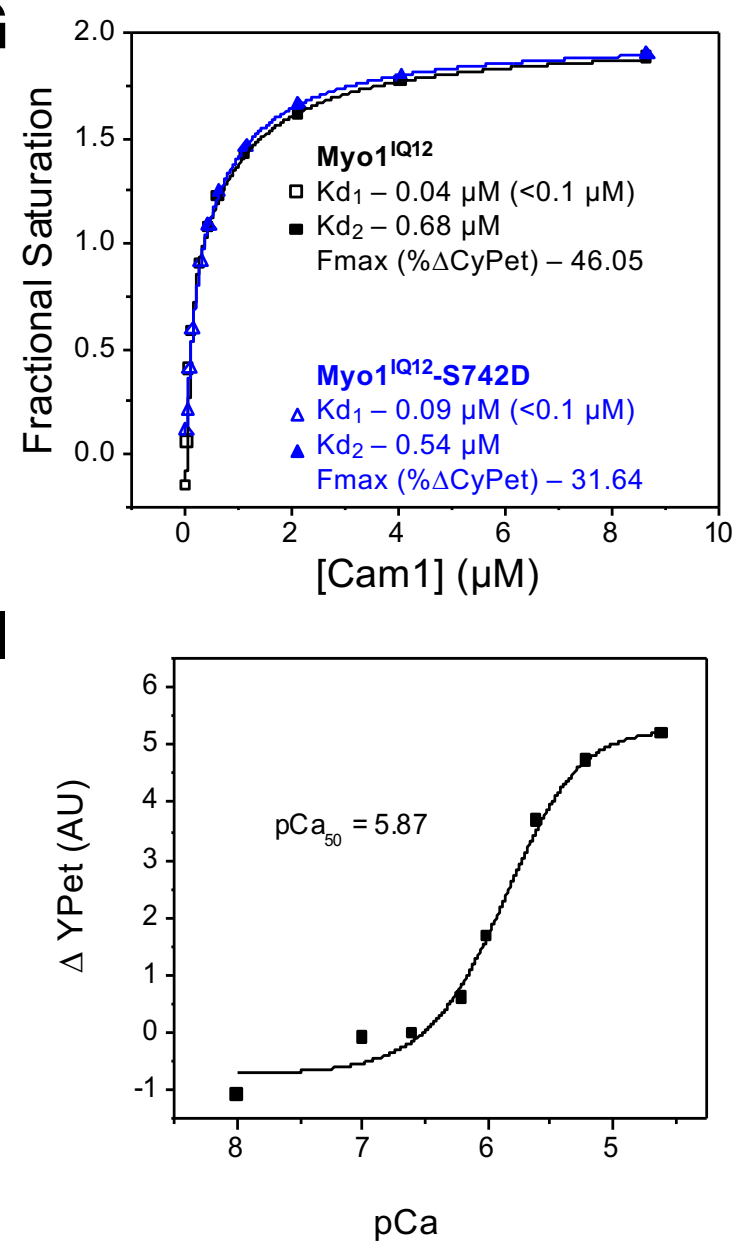

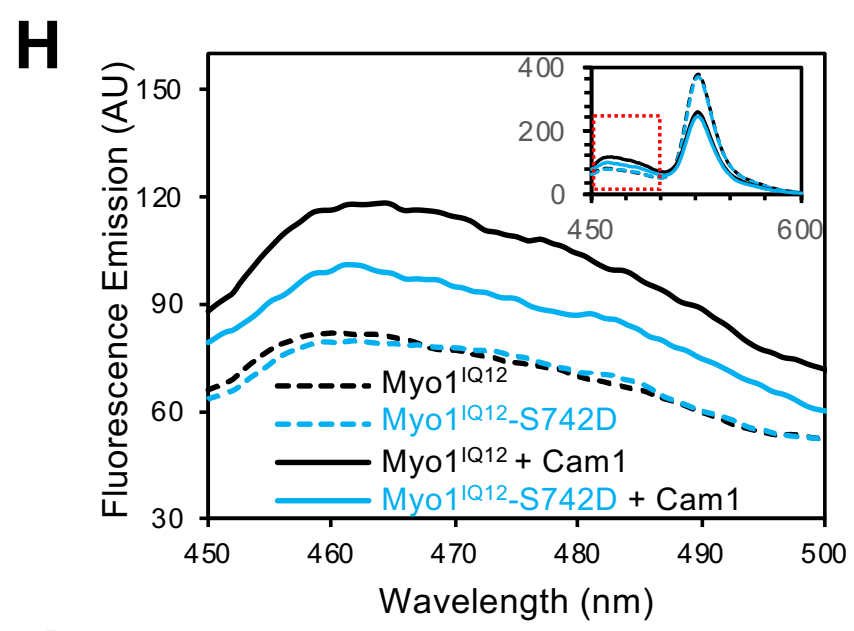

J

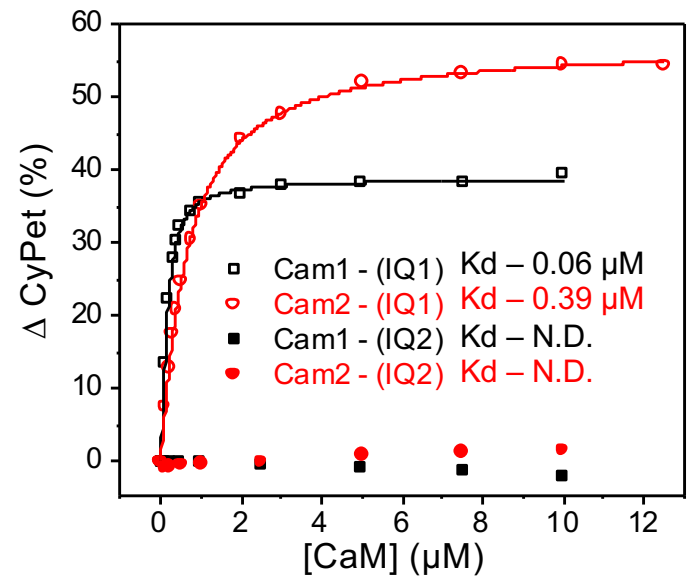




\section{Figure 3}
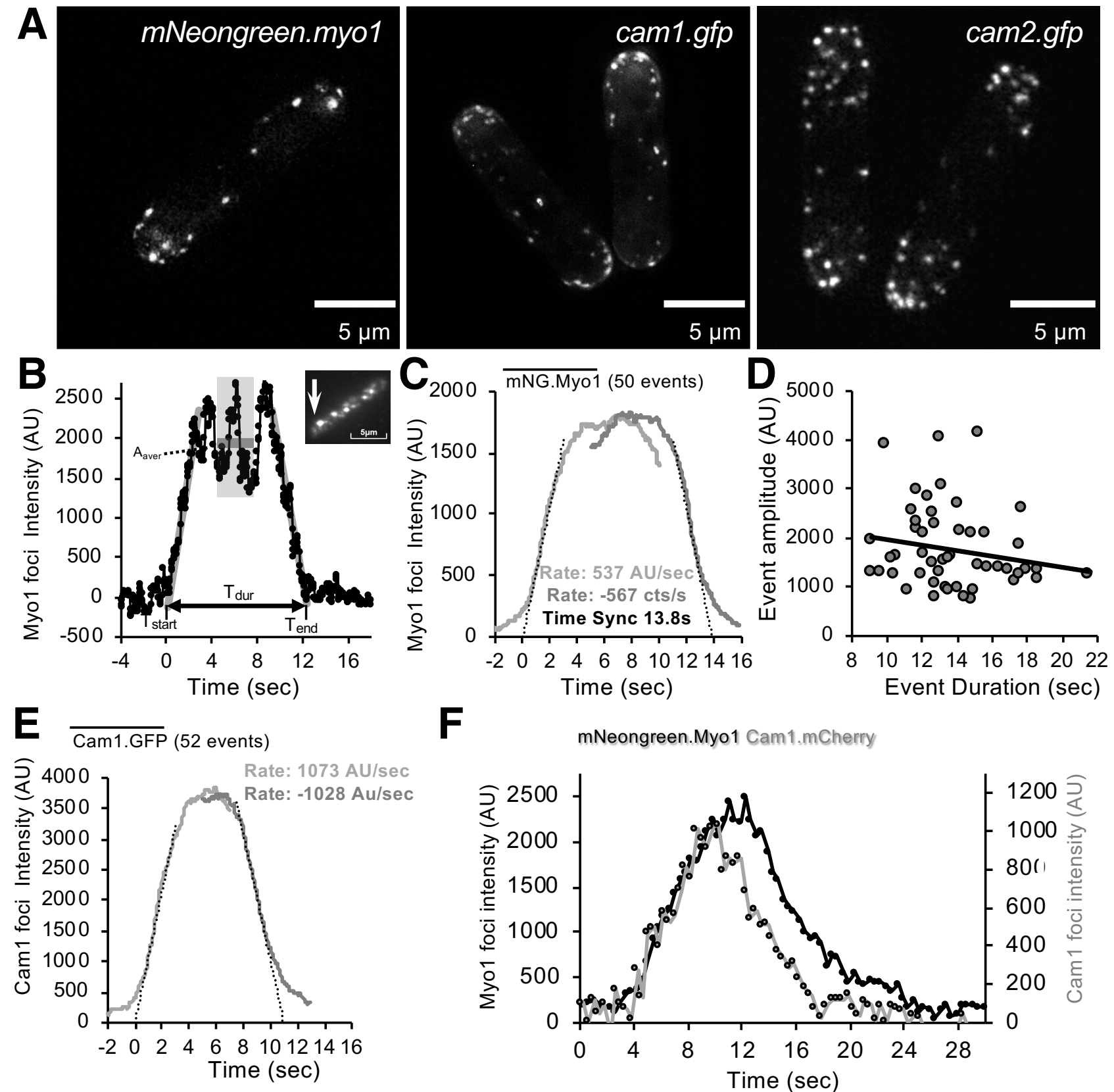

$\mathbf{F}$

mNeongreen.Myo1 Cam1.mCherry
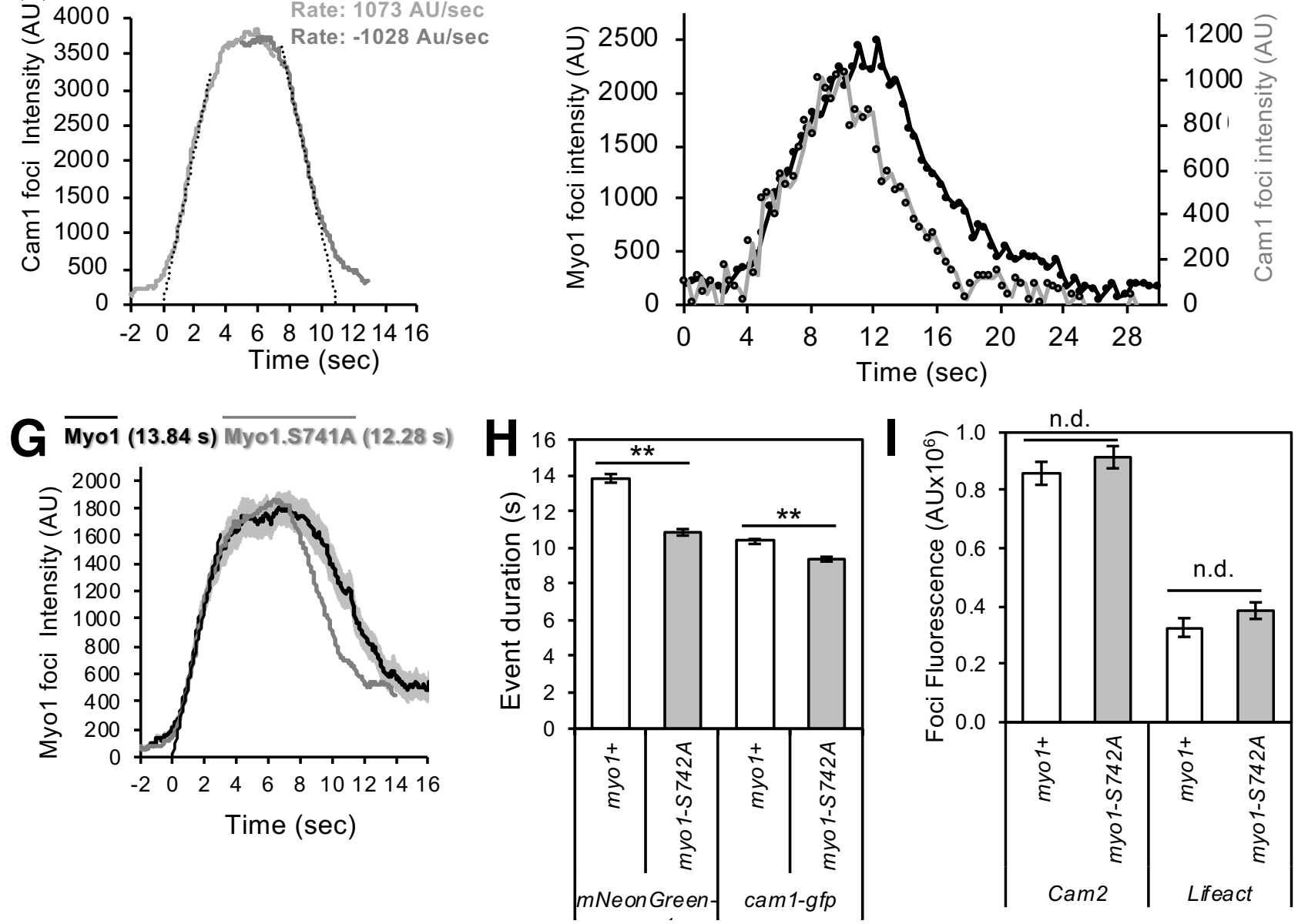


\section{Figure 4}

A

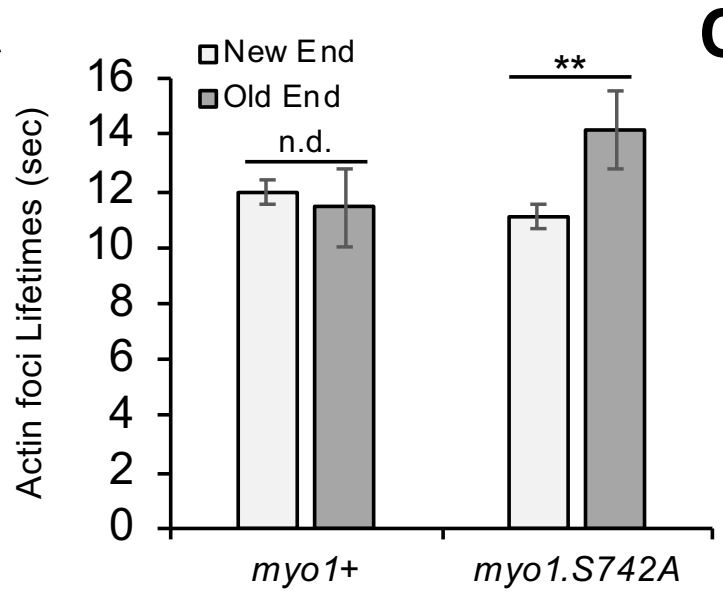

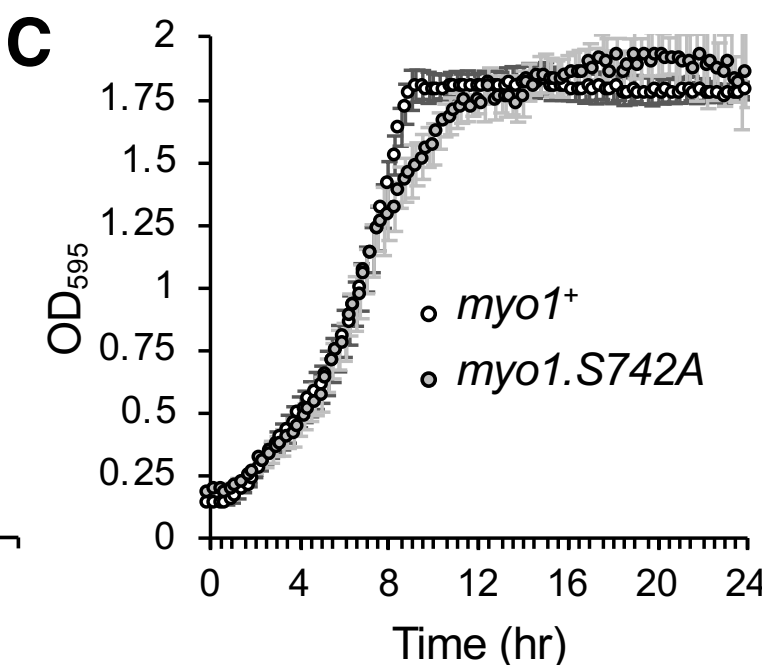

B
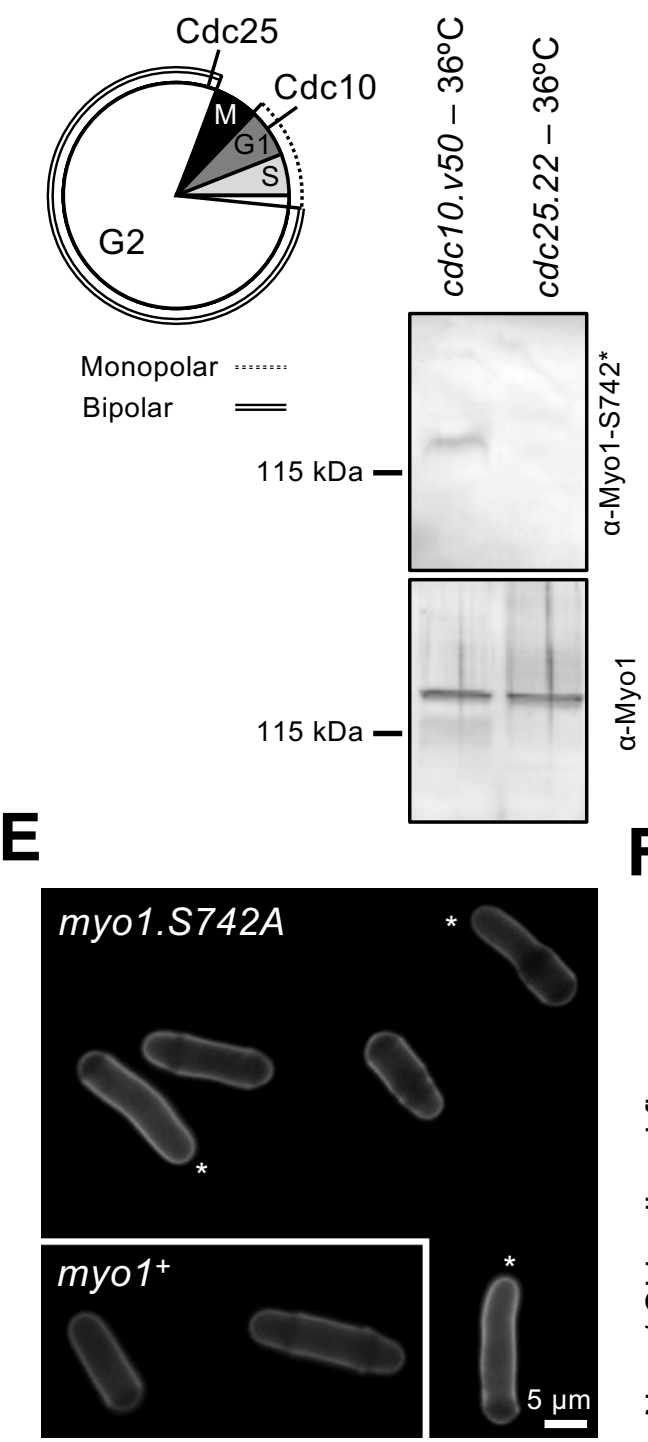

D

mNeongreen

Transmitted

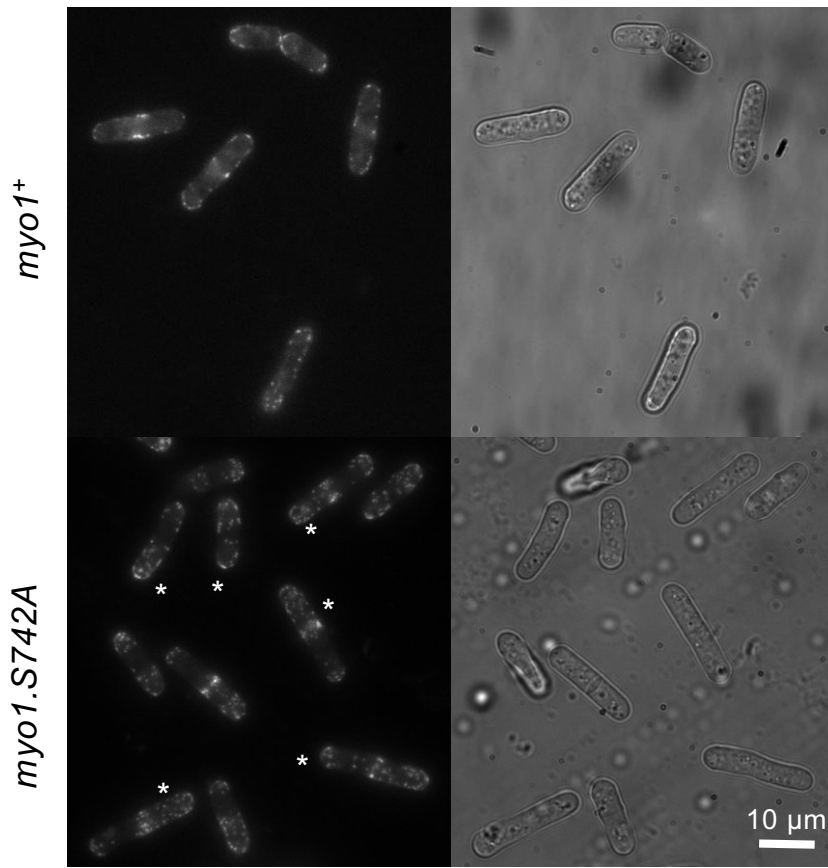

F

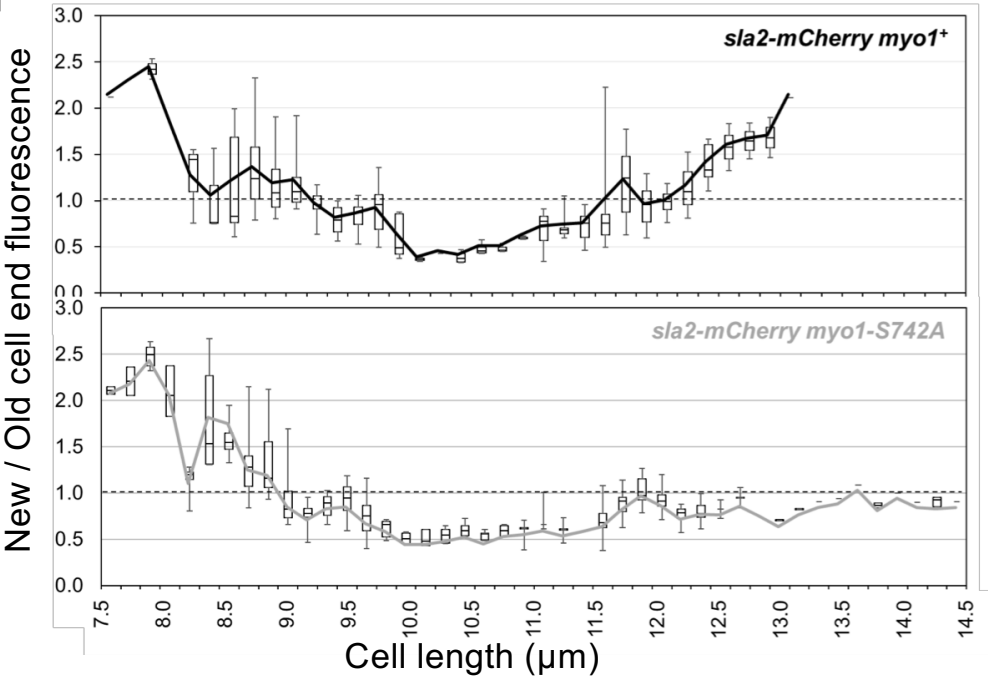




\section{Figure 5}

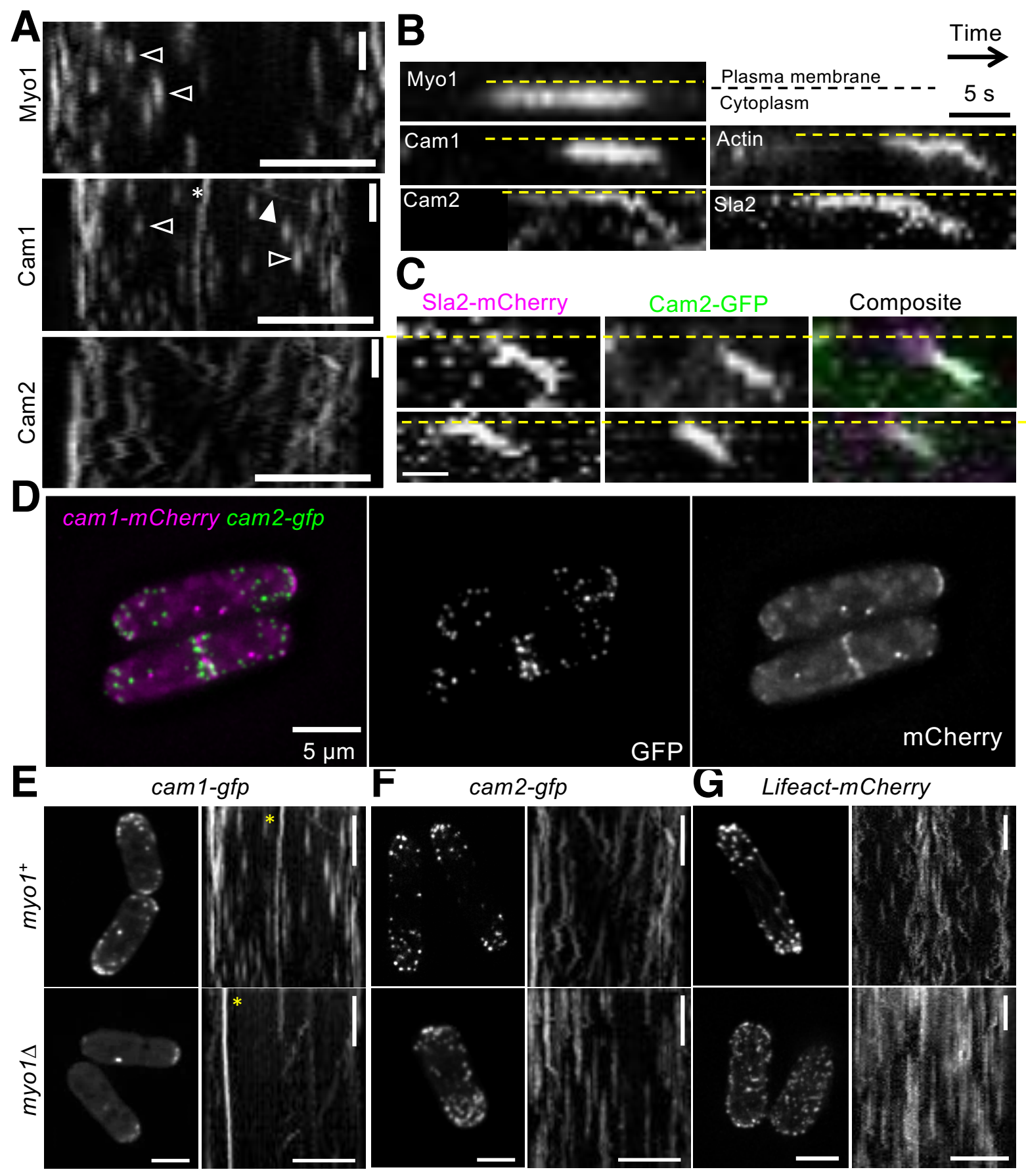


Figure 6

A

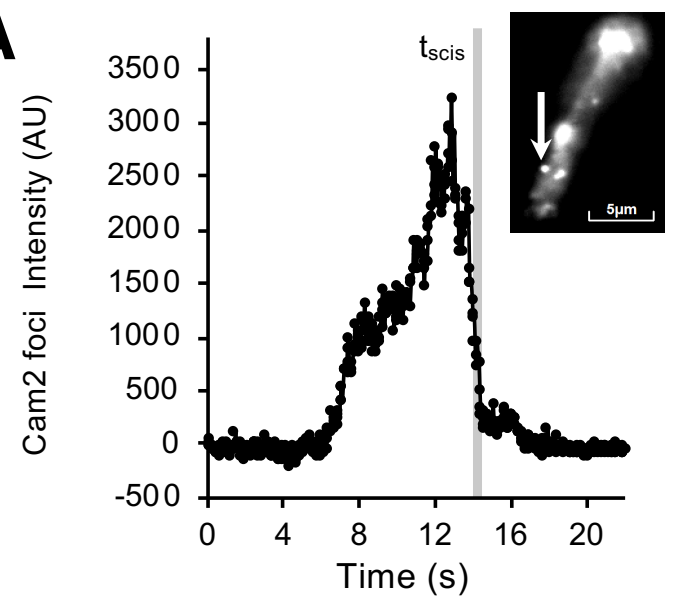

C

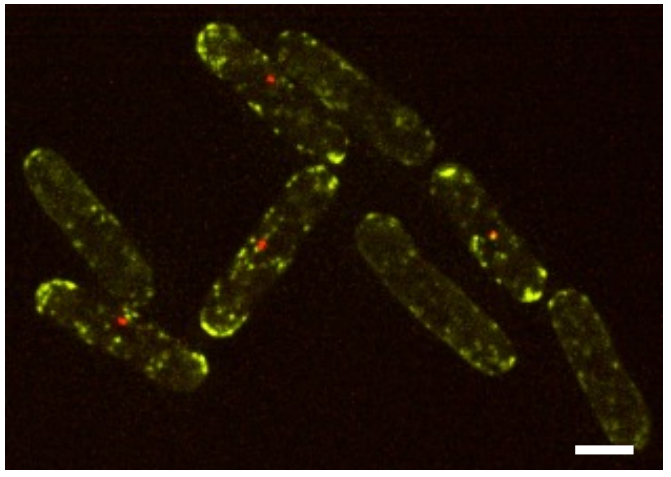

E

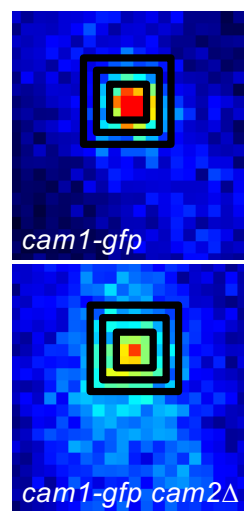

Region 1

Region 2

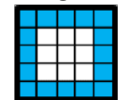

Region 3

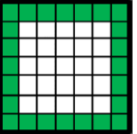

G

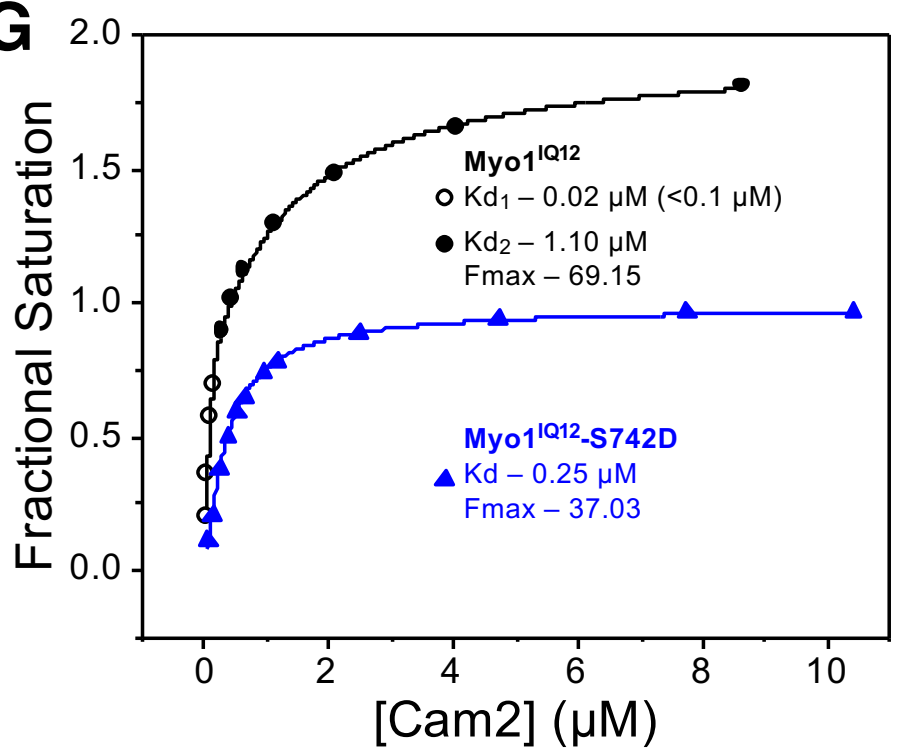

B

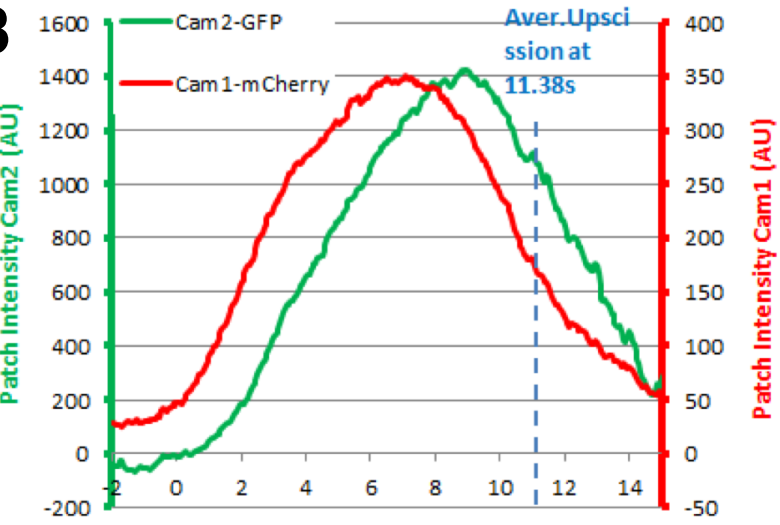

Time (s)

D

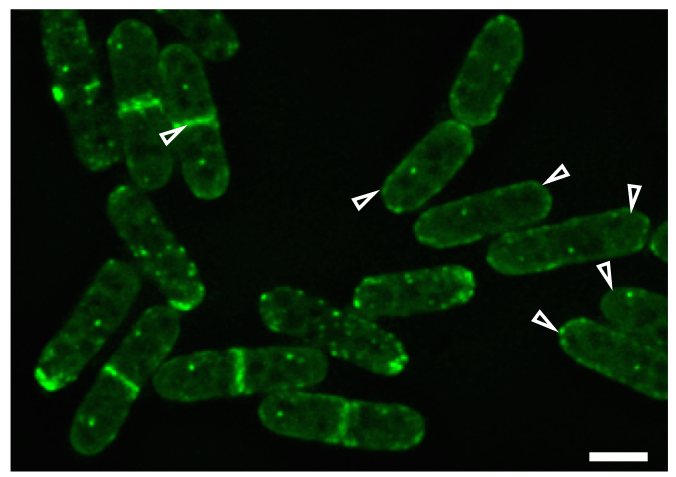

E

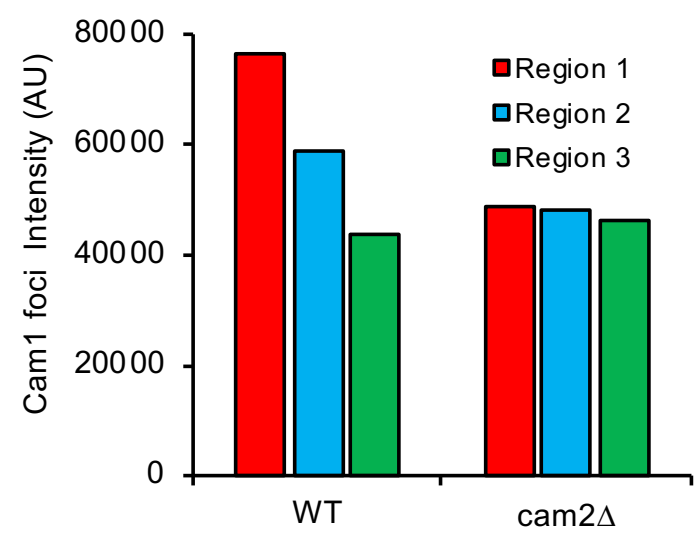

H

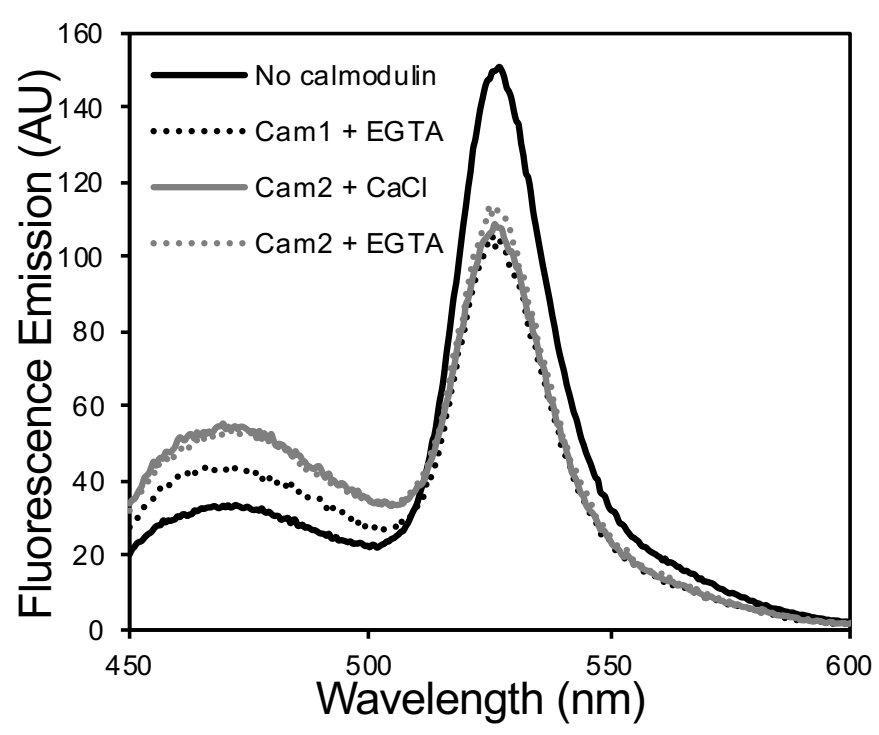




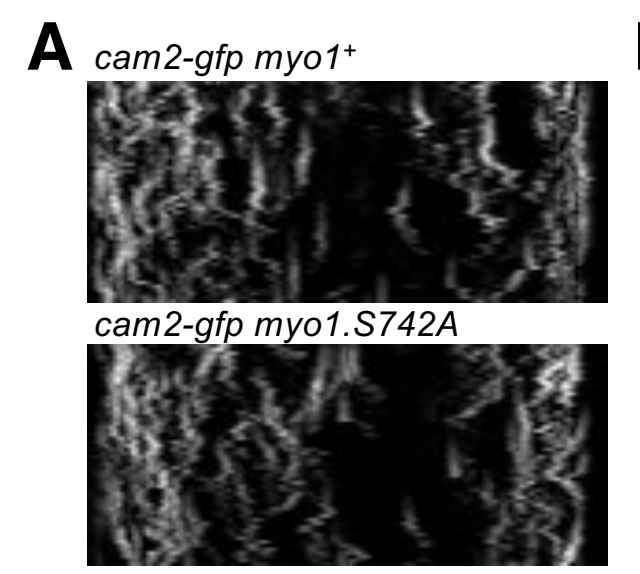

B Unphosphorylated

Phosphorylated

$-\mathrm{Ca}^{2+}$
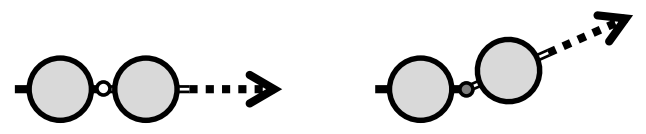

$+\mathrm{Ca}^{2+}$
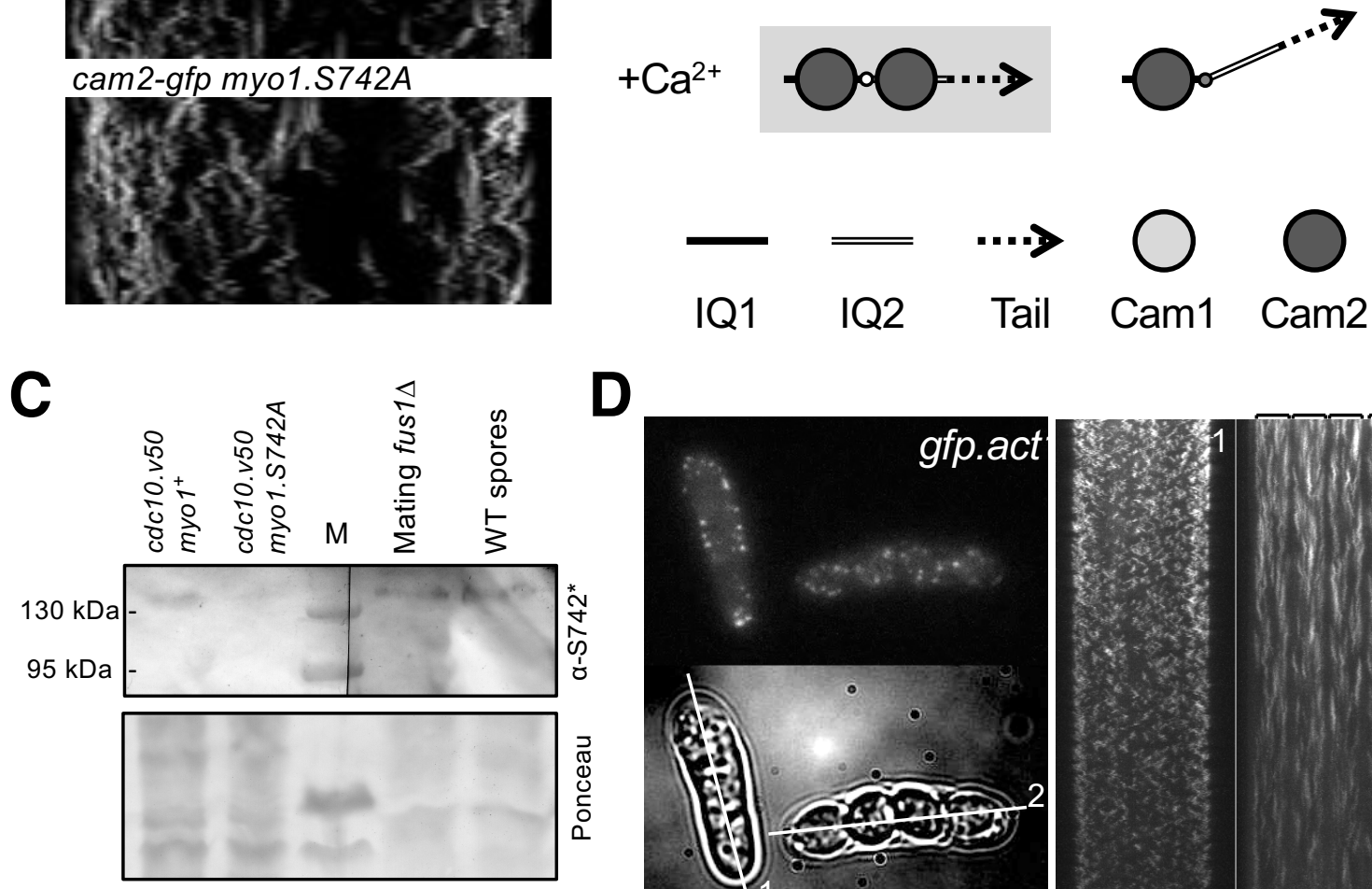

D
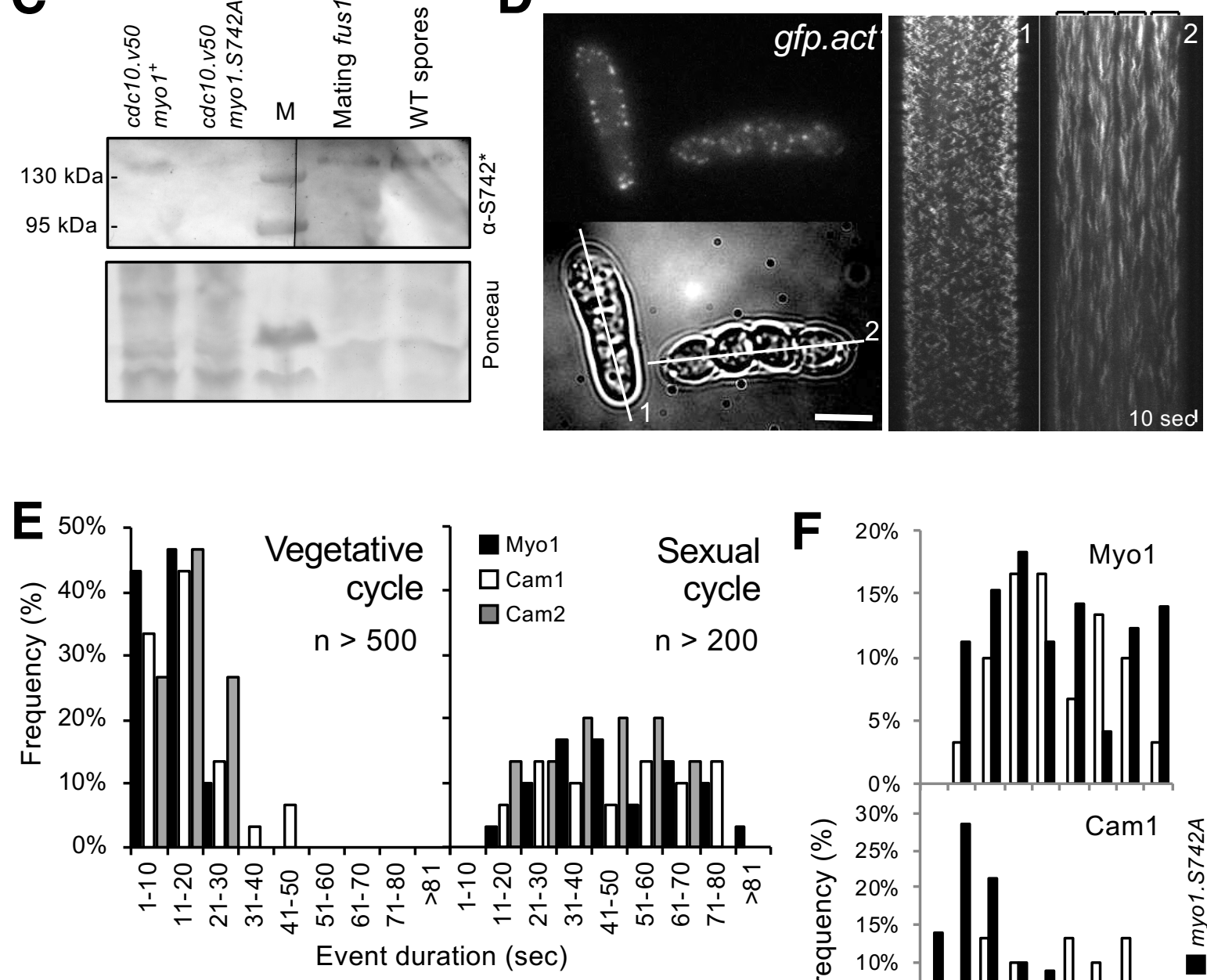

G
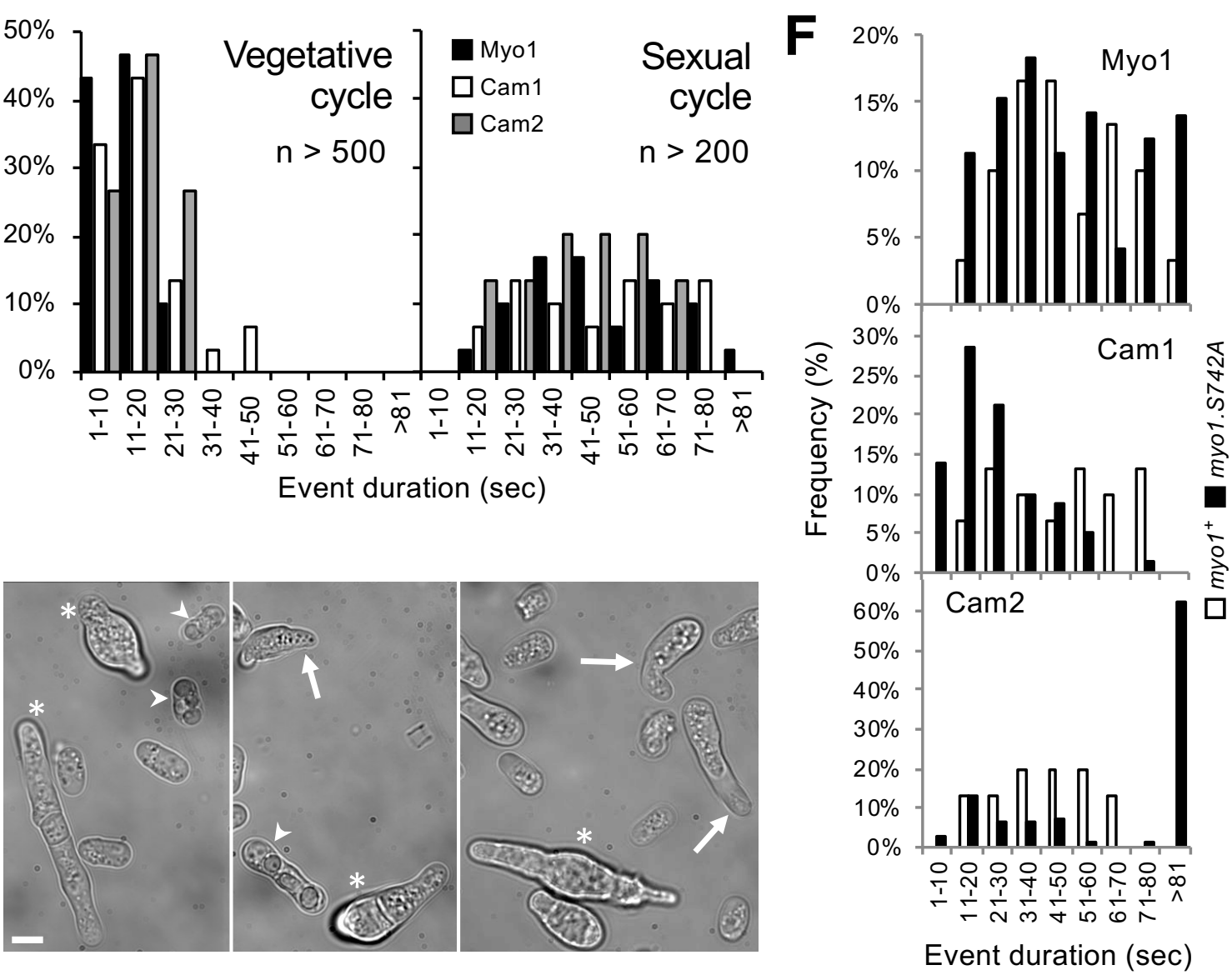
Figure 8

A

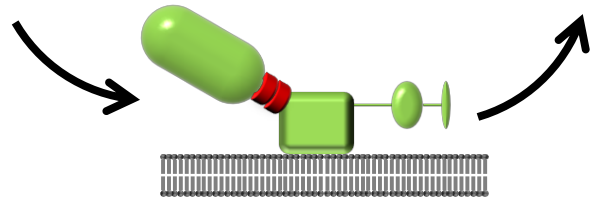

B

$\longrightarrow$

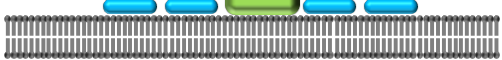

C

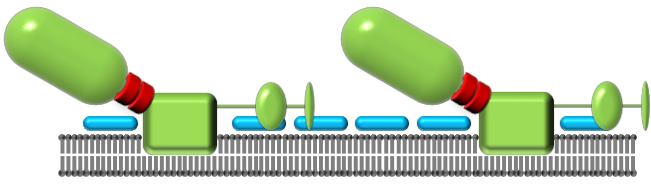

D

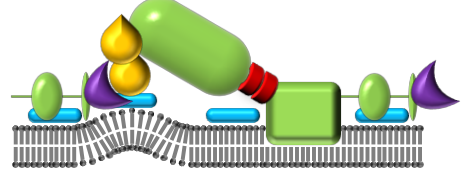

E

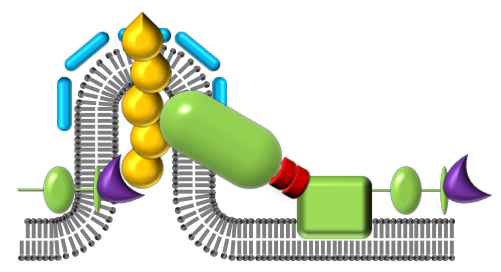

F

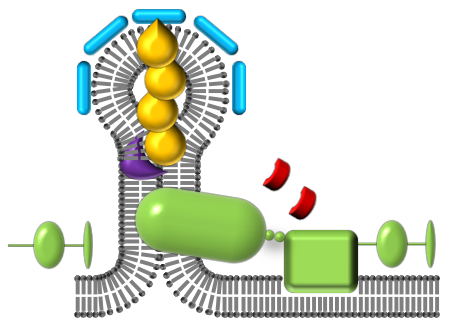

